Board of Governors of the Federal Reserve System

International Finance Discussion Papers

Number 1303

September 2020

\title{
Trade Credit, Markups, and Relationships
}

Alvaro Garcia-Marin, Santiago Justel, and Tim Schmidt-Eisenlohr

Please cite this paper as:
Garcia-Marin, Alvaro, Santiago Justel, and Tim Schmidt-Eisenlohr $(2020)$.
Credit, Markups, and Relationships," International Finance Discussion Pa-
pers 1303. Washington: Board of Governors of the Federal Reserve System,
https://doi.org/10.17016/IFDP.2020.1303.

NOTE: International Finance Discussion Papers (IFDPs) are preliminary materials circulated to stimulate discussion and critical comment. The analysis and conclusions set forth are those of the authors and do not indicate concurrence by other members of the research staff or the Board of Governors. References in publications to the International Finance Discussion Papers Series (other than acknowledgement) should be cleared with the author(s) to protect the tentative character of these papers. Recent IFDPs are available on the Web at www.federalreserve.gov/pubs/ifdp/. This paper can be downloaded without charge from the Social Science Research Network electronic library at www.ssrn.com. 


\title{
Trade Credit, Markups, and Relationships*
}

\author{
Alvaro Garcia-Marin ${ }^{\dagger} \quad$ Santiago Justel ${ }^{\ddagger} \quad$ Tim Schmidt-Eisenlohr $^{\S}$
}

31st August 2020

\begin{abstract}
Trade credit is the most important form of short-term finance for firms. In 2019, U.S. non-financial firms had about $\$ 4.5$ trillion in trade credit outstanding equaling 21 percent of U.S. GDP. This paper documents two striking facts about trade credit use. First, firms with higher markups supply more trade credit. Second, trade credit use increases in relationship length, as firms often switch from cash in advance to trade credit but rarely away from trade credit. These two facts can be rationalized in a model where firms learn about their trading partners, sellers charge markups over production costs, and financial intermediation is costly. The model also shows that saving on financial intermediation costs provides a strong rationale for the dominance of trade credit. Using Chilean data at the firm-product-level and the trade-transaction level, we find support for all predictions of the model.
\end{abstract}

Keywords: Trade credit, markups, financial intermediation, learning

JEL Classification: F12, F14, G21, G32

${ }^{*}$ We would like to thank JaeBin Ahn, Julia Cajal Grossi, Tore Ellingson, Ryan Kim, as well as seminar audiences at the Graduate Institute Geneva, ETH Zurich, University of Bayreuth, George Washington University, Universidad de Chile, Universidad Alberto Hurtado, Universidad de Santiago, University of Mainz, and the IDB Research Seminar, and conference participants at the CESifo Conference on Global Economy, LACEA-LAMES, Mid-Atlantic International Trade Workshop, Midwest Trade Conference, SED Conference, and RIDGE Conference, for helpful comments and suggestions. The views expressed are the authors' and do not necessarily represent the views of the Federal Open Market Committee, its principals, or the Board of Governors of the Federal Reserve System. Alvaro García-Marin gratefully acknowledges research support from ANID-Chile through project Fondecyt Regular 1191536.

${ }^{\dagger}$ Universidad de los Andes. Email: agarciam@uandes.cl

${ }^{\ddagger}$ World Bank. Email: sjustel@ucla.edu

${ }^{\S}$ Federal Reserve Board of Governors. Email: t.schmidteisenlohr@gmail.com 


\section{Introduction}

Trade credit is the most important form of short-term finance for U.S. firms. ${ }^{1}$ In 2019, nonfinancial U.S. firms had about $\$ 4.5$ trillion in trade credit outstanding equaling 21 percent of GDP. Trade credit affects key economic outcomes like economic growth (Fisman and Love, 2003; Demirguc-Kunt and Maksimovic, 2001), corporate default (Jacobson and von Schedvin, 2015; Barrot, 2016; Amberg et al., Forthcoming), and the transmission of monetary policy (Adelino et al., 2020). ${ }^{2}$

While there is a large literature on trade credit, detailed micro evidence on its use is still limited, in particular on the choice between trade credit and its main alternative, cash in advance. $^{3}$ This paper provides unique evidence on this choice, using transaction-level data on Chilean exports. A key advantage of looking at international data is that it provides more variation to study payment choice at the extensive margin, as trade credit is far less dominant for cross-border transactions.

We begin by documenting two striking facts about trade credit use that are illustrated in figure 1. First, firms with higher markups supply more trade credit (panel A); second, trade credit use increases with relationship length (panel B). ${ }^{4}$

[Figure 1 here]

We then present a model of trade credit choice that can rationalize these two facts and the dominance of trade credit, as well as additional facts that we discuss below. ${ }^{5}$ In the model firms charge positive markups, there is a financial intermediation friction, and buyers and sellers learn about each other through repeated interactions. Learning matters because firms can be reliable or unreliable and because there is a commitment problem: A buyer may not pay after receiving goods on trade credit and a seller may not deliver after getting paid cash in advance.

\footnotetext{
${ }^{1}$ Trade credit is defined as the implicit lending by a seller to a buyer when a buyer is given some time to pay for goods after receiving them.

${ }^{2}$ In addition, see Nilsen (2002) on trade credit and the bank lending channel and Love et al. (2007) on trade credit use in emerging economies in the wake of financial crises.

${ }^{3}$ Some notable exceptions that have used contract-level data are Giannetti et al. (2011), Murfin and Njoroge (2014), Antràs and Foley (2015), Barrot (2016), and Amberg et al. (2020).

${ }^{4}$ Figure A.1 in appendix E shows that the same relationship holds for aggregate U.S. data when plotting total trade of the U.S. non-financial sector over U.S. GDP against the log of aggregate U.S. markups, as estimated by De Loecker and Warzynski (2012). See also figure A.2 that shows the development of trade credit and markups over time in the United States.

${ }^{5}$ While the static model extends Schmidt-Eisenlohr (2013), the dynamic extension builds on Araujo et al. (2016) and Antràs and Foley (2015).
} 
The model provides two key insights. First, if there are positive markups, and banks charge a higher interest rate on borrowing than they pay on deposits, then trade credit has a financial cost advantage. Earlier work has argued that trade credit is an inferior financing form and should be more expensive than bank credit because banks have access to cheaper refinancing. ${ }^{6}$ However, the key point of our model is that in the typical environment where firms have no excess liquidity, for any transaction, either the exporter or the importer has to borrow from a bank. Hence, the question is not if bank finance is cheaper than a firm's internal cost of funds, but rather if financing through the buyer or the seller is cheaper. We show that if there are positive markups, then borrowing by the seller tends to be cheaper because the amount borrowed is smaller, as trade credit only requires borrowing the production costs. In contrast, cash in advance requires borrowing the full invoice.

Second, as firms learn about their trading partners, the importance of the commitment problem declines and the financial cost advantage of trade credit starts to dominate. As a consequence, new relationships often rely on cash in advance, whereas transactions within old firm relationships are exclusively based on trade credit (as in panel B of figure 1). Our findings expand both empirically and theoretically on Antràs and Foley (2015), who found that sales by a large U.S. poultry exporter shifted towards trade credit within relationships over time. First, we document that trade credit use increases with relationship length, using comprehensive data on Chilean export transactions. Second, we show that, under weak conditions, the use of trade credit increases with relationship length even if there is a commitment problem on the seller side and both firms learn about each other. This more general result only holds when there is a financial cost advantage of trade credit. $^{7}$

In the model, a seller produces a good that can be sold at a markup to a final consumer. The seller does not sell directly to the final consumer but trades with another firm in the destination country, settling the transaction either through trade credit or cash in advance. ${ }^{8,9}$ As financial

\footnotetext{
${ }^{6}$ See, for example, the discussion in Ellingsen et al. (2016).

${ }^{7} \mathrm{~A}$ generalization of the Antràs and Foley (2015) learning model to two-sided learning should instead imply both switches from cash in advance to trade credit as well as switches from trade credit to cash in advance, with switches in both directions at the same frequency.

${ }^{8}$ We abstract from a third financing form, letter of credit, where banks help resolve the commitment problem against a fee, for three reasons. First, in the data, markups and relationship length correlate with trade credit and cash in advance but not with letters of credit use. Second, letters of credit are only used for international transactions and our model aims at modeling the general trade credit choice. Finally, letters of credit are relatively expensive and are therefore only used for specific large transactions. For details on letter of credit as well as the less-used additional alternative, documentary collections, see Niepmann and Schmidt-Eisenlohr (2017a).

${ }^{9}$ There may also be a partial advance-payment, on which data is even more limited. In our data from Chile two-part contracts (partial cash in advance) represent only $0.2 \%$ of transactions. Similarly, Antràs and Foley
} 
intermediation is costly and the borrowing rate exceeds the deposit rate, the difference in borrowing needs between cash in advance and trade credit affects profits. Under cash in advance, the buyer needs to pre-pay the full amount to the seller which requires borrowing an amount equal to the full invoice. In contrast, extending trade credit requires less borrowing, as the seller only needs to cover her production costs in advance which may be substantially lower than the sales price if there is a markup. Thus, the larger are the markup and the difference between the borrowing and the deposit rate, the more attractive is trade credit. All else equal, trade credit is preferred over cash in advance if there is a positive markup and a positive interest rate spread. As the world typically features positive markups and positive interest rate spreads, the theory thus provides a clear rationale for the dominance of trade credit in firm-to-firm transactions.

We then extend the model to a dynamic setup where firms learn about the reliability of their trading partners through repeated interactions. Then, as learning reduces the importance of enforcement frictions and thereby raises the importance of the financial cost advantage of trade credit, trade credit use increases with relationship length. This rationale also implies that the effects of learning are stronger for more complex products for which learning is more central.

We test the model using two rich panel datasets of Chilean firms. First, we construct markup estimates at the firm-product level using detailed production data on inputs and outputs of Chilean plants following the method developed by De Loecker et al. (2016). We then combine these markup estimates with transaction-level trade data, which contains detailed information on the payment choice to test the predictions of the model. To address endogeneity concerns regarding the markups, we implement a 2SLS strategy using plant-product physical productivity as an instrument for markups. ${ }^{10}$

We find that trade credit use increases with markups and that this effect increases with the difference between the buyer's borrowing rate and the seller's deposit rate. In line with the model's prediction, the effect of the markup also increases with the destination country's rule of law. Results are robust to alternative measures of markups, and to the inclusions of a large set of fixed effect and control variables. When instrumenting the markup by plant-product level physical productivity, the markup coefficient becomes substantially larger and remains highly significant. Taken together, these results provide strong support for our key prediction

(2015) report that the firm they study does not rely on two-part contracts.

${ }^{10}$ We show that a simple extension with variable markups to the baseline model provides a rationale for this instrument. More importantly, we show that the predictions for markups also hold with variable markups. More efficient firms charge higher markups, and this makes trade credit use more attractive, as a larger markup increases the financial cost advantage of trade credit. 
that trade credit use increases with markups, and that the effect of markups is stronger when financial intermediation is more costly.

We also find strong support for the dynamic predictions of the model. Trade credit use increases with relationship length due to an asymmetry in the dynamic behavior of firms: While firms switch their payment terms within a relationship from cash in advance to trade credit quite frequently, they rarely switch in the opposite direction (consistent with the financial cost advantage of trade credit). Moreover, relationship length affects the payment choice more for trade with low rule-of-law destinations and for differentiated products. Finally, relationship length is particularly important for younger relationships, whereas markups matter the most for older relationships.

The paper contributes to several strands of the literature, by providing new facts and evidence on trade credit, adding to earlier work that relied on domestic data (see e.g. Petersen and Rajan, 1997; Giannetti et al., 2011; Murfin and Njoroge, 2014; Barrot, 2016; Amberg et al., 2020) and international data (see Antràs and Foley, 2015), and by extending earlier theories on trade credit and payment choice (in particular, Schmidt-Eisenlohr, 2013; Antràs and Foley, 2015). ${ }^{11}$

First, by showing that trade credit use increases with markups, it speaks to the literature on competition and trade credit (Peura et al., 2017; Giannetti et al., 2018; Chod et al., 2019), which links trade credit to market power. In our model, markups affect trade credit choice as they imply lower borrowing needs and hence lower financial costs under trade credit. This mechanism is quite distinct and complementary to the effects that arise from market power and competition. Both channels likely contribute to the positive relationship between trade credit and markups that we document. However, the additional finding that the effect of markups rises in destination-country financial costs represents more specific evidence for our channel. ${ }^{12}$

Second, our evidence on the role of relationship length based on comprehensive data on Chilean export transactions and our dynamic model extension expand on research that looked at individual case studies (see Antràs and Foley, 2015, on exports by one U.S. poultry exporter)

\footnotetext{
${ }^{11}$ For international evidence with more aggregate data, see also Hoefele et al. (2016) and Demir and Javorcik (2018). Additional theoretical work on the payment choice includes Ahn (2014), Olsen (2016), and Fischer (2020). For papers studying the broader relationship of financial constraints and international trade, see among others Amiti and Weinstein (2011), Ahn et al. (2011), Chor and Manova (2012), Manova (2013), Paravisini et al. (2014), Niepmann and Schmidt-Eisenlohr (2017b), and Ahn and Sarmiento (2019).

${ }^{12}$ The evidence on markups is also broadly consistent with predictions from the inventory model in Daripa and Nilsen (2011), and with earlier evidence in Petersen and Rajan (1997) who find that firms with larger gross profit margins over costs extend more trade credit. As gross profit margins can arguably be seen as a rough proxy for markups, their findings are thus consistent with the model presented here.
} 
or survey data (McMillan and Woodruff, 1999).

Third, our theory proposes a new mechanism for why trade credit is so dominant: Trade credit minimizes total borrowing from banks, thereby reducing financial costs, when firms charge positive markups and when financial intermediation is costly. Burkart and Ellingsen (2004) propose a prominent and complementary explanation, where sellers extend trade credit because this type of credit is "in-kind" and is thus harder to divert than cash. In recent followup work, Amberg et al. (2020) extend this model with a labor-capital choice, showing that trade credit contributes to a capital-bias for financially constrained firms. Schwartz (1974) and Ferris (1981) suggest models where trade credit serves a transaction motive, separating the exchange of goods from the exchange of money. Brennan et al. (1988), Schwartz and Whitcomb (1979), and Mian and Smith (1992) rationalize trade credit use as a way to price discriminate. The idea in our model that trade credit provides a way to save on financial costs is related to earlier work, where trade credit helps channel excess liquidity across firms (Emery, 1984). ${ }^{13}$ In addition, the assumption in our model that borrowing rates are higher than deposit rates could in part reflect informational advantages of suppliers over banks (see Smith, 1987; Biais and Gollier, 1997). For an early summary of the main theories on trade credit, see also Petersen and Rajan (1997).

Finally, the theory on trade credit developed here generalizes and extends earlier work on payment choice in multiple ways: (i) It shows how introducing markups and a financial intermediation cost generates a financial cost advantage for trade credit; (ii) it shows how the model in Schmidt-Eisenlohr (2013) (and Antràs and Foley, 2015) can be extended to a setting with arbitrary bargaining power based on the Neutral Bargaining Solution by Myerson (1984); (iii) it generalizes the learning results in Antràs and Foley (2015) to the case of two-sided learning and derives conditions on the speed of learning; (iv) it solves the model for variable markups; (v) and it rationalizes a set of new findings on trade credit and the interactions between learning, markups, contract enforcement, and product complexity.

The remainder of the paper is organized as follows. Section 2 presents the model of payment choice and derives the main testable predictions. Section 3 discusses the empirical specifications and presents the methodology for deriving firm-product markups. Section 4 describes our dataset. Section 5 presents the empirical results. Finally, section 6 discusses the implications of our study and routes for future research.

\footnotetext{
${ }^{13}$ See also Ahn (2014), who also studies this mechanism and tests it with Chilean and Colombian data.
} 


\section{A model of trade credit and markups}

In this section, we extend the models in Schmidt-Eisenlohr (2013) and Antràs and Foley (2015), and show how a positive markup and a financial intermediation cost can simultaneously explain two striking facts: First, almost all firm-to-firm interactions rely on trade credit. Second, trade credit use increases within trade relationships over time.

In the model, there are three key elements. First, there is a time delay between the production of the goods by the seller and the sale of the goods by the buyer. Second, financing is costly. To pay for goods or production costs, firms need to borrow funds from the financial sector. Firms can also deposit surplus liquidity as deposits with the banking sector. Importantly, because of regulation, monitoring, and general overhead costs, banks charge a higher interest rate when lending funds to firms than the interest rates they pay to depositors. ${ }^{14}$ Third, there is a commitment problem and imperfect contract enforcement. When a buyer or seller does not fulfill its contractual obligation, its trading partner can sue it in court. This is, however, only successful with a certain probability. ${ }^{15}$

\subsection{Model setup}

One buyer is matched with one seller. Both firms are risk-neutral. A fraction $\eta\left(\eta^{*}\right)$ of sellers (buyers) is reliable; that is, these firms always fulfill their contracts. ${ }^{16}$ If a firm is unreliable and thus does not fulfill its contract voluntarily, the other firm can try to enforce the agreement in court, which is successful with probability $\lambda\left(\lambda^{*}\right)$. When facing an opportunity to cheat, a random seller thus fulfills the contract with probability $\tilde{\lambda} \equiv \eta+(1-\eta) \lambda$, and a random buyer with probability $\tilde{\lambda}^{*} \equiv \eta^{*}+\left(1-\eta^{*}\right) \lambda^{*}$.

There are two periods. In period 0 , the seller produces the goods and sends them to the buyer. In period 1 , the buyer sells the goods to a final consumer. Because of this time gap between production and final sale, firms need to agree on payment terms. They have two options. First, buyers can pay in advance (cash in advance); that is, the buyer pays before receiving the goods. Second, they can trade on an open account, where the buyer pays after delivery; that is, the seller extends trade credit to the buyer. A seller produces output for a

\footnotetext{
${ }^{14}$ This interest rate difference may be further increased by borrower risk. The point here is that abstracting from the pricing of risk, financial intermediation by banks is costly.

${ }^{15}$ An alternative interpretation would be that all contracts get enforced in court eventually but this generates a legal cost as well as a time delay in settlement.

${ }^{16}$ For the remainder of the paper, all variables related to the buyer are denoted with an asterisk.
} 
total cost of $C$ and sells it to the buyer. The buyer can then sell the goods to final consumers and generate revenues $R$. For now, we take $R$ and $C$ as exogenous. In section 2.5.2, we show how our results extend to a model with linear demand and variable markups, and in appendix B.1 we derive results with CES preferences.

To finance their transactions, firms can borrow from banks at an interest rate $r_{b}\left(r_{b}^{*}\right)$. Firms can deposit surplus funds at banks for a deposit rate of $r_{d}\left(r_{d}^{*}\right)$. The seller makes a take-itor-leave-it offer to the buyer who can choose to accept or reject the offer. In section 2.5.1, we extend the model to allow the seller and the buyer to bargain over the surplus with bargaining weights $\theta$ and $1-\theta$, respectively. ${ }^{17}$

We assume that parameters are such that sellers always offer contracts that are acceptable to both types of buyers, and that unreliable sellers always imitate reliable sellers when choosing the optimal contract. In appendix B.2, we provide the precise conditions under which these assumptions hold. The conditions are relatively weak and either always hold, or require some minimum markup to hold. ${ }^{18}$

Trade Credit Under trade credit, the seller maximizes:

$$
\begin{aligned}
\mathrm{E}\left[\Pi_{S}^{T C}\right] & =\tilde{\lambda}^{*} P^{T C}-\left(1+r_{b}\right) C \\
\text { s.t. } \mathrm{E}\left[\Pi_{R B}^{T C}\right] & =R-P^{T C} \geq 0
\end{aligned}
$$

where $P^{T C}$ is the total payment from the buyer to the seller. Under trade credit, the seller gets paid $P^{T C}$ with probability $\tilde{\lambda}^{*}$, while incurring the production $\operatorname{costs} C$ with certainty. Because production takes place in period 0 while sales only take place in period 1 , the seller has to borrow the production costs $C$ from a bank and pay the interest rate $r_{b}$. The maximization is subject to the participation constraint of a reliable buyer, which requires non-negative profits for the buyer. Solving for the optimal $P^{T C}$ that respects the participation constraint implies $P^{T C}=R$, delivering expected profits of:

$$
\mathrm{E}\left[\Pi_{S}^{T C}\right]=\tilde{\lambda}^{*} R-\left(1+r_{b}\right) C .
$$

\footnotetext{
${ }^{17}$ As there is private information about the type of buyer and seller, we follow Myerson (1984) and apply the Neutral Bargaining Solution, which generalizes Nash bargaining to a setting with private information.

${ }^{18}$ For example, if $\eta, \eta^{*}, \lambda$, and $\lambda$ are each greater or equal to 0.8 , and there is an enforcement cost of 5 percent (not modeled in the baseline to ease the exposition), then revenues have to be at least 1.07 and 1.08 times production costs, respectively.
} 
Cash in Advance Under cash in advance, a reliable seller maximizes:

$$
\begin{aligned}
\mathrm{E}\left[\Pi_{R S}^{C I A}\right] & =\left(1+r_{d}\right)\left(P^{C I A}-C\right), \\
\text { s.t. } \mathrm{E}\left[\Pi_{B}^{C I A}\right] & =\tilde{\lambda} R-\left(1+r_{b}^{*}\right) P^{C I A} \geq 0 .
\end{aligned}
$$

Under cash in advance, any seller gets paid $P^{C I A}$ with certainty. At the same time, a reliable seller incurs production costs $C$ with certainty as well. If the price charged to the buyer exceeds production costs, the seller deposits the surplus funds at a bank for interest rate $r_{d}$. The buyer can only sell the goods if she receives them. Thus, she generates revenues $R$ with probability $\tilde{\lambda}$. The buyer pays $P^{C I A}$ with certainty in period 0 , borrowing from a bank at interest rate $r_{b}^{*}$. Solving for the optimal $P^{C I A}$ delivers $P^{C I A}=\frac{\tilde{\lambda}}{1+r_{b}^{*}} R$. With expected profits of:

$$
\mathrm{E}\left[\Pi_{R S}^{C I A}\right]=\left(1+r_{d}\right)\left(\frac{\tilde{\lambda}}{1+r_{b}^{*}} R-C\right) .
$$

This represents the general solution for all sellers, as we assumed that conditions are such that an unreliable seller always imitates a reliable seller (see appendix B.2 for details).

Optimal Contract Combining equations (1) and (2) implies that the seller chooses trade credit if:

$$
\tilde{\lambda}^{*} R-\left(1+r_{b}\right) C-\left(1+r_{d}\right)\left(\frac{\tilde{\lambda}}{1+r_{b}^{*}} R-C\right)>0 .
$$

Now, assume that firms charge a constant markup to final consumers given by $\mu$ so that $R=\mu C$. We relax this assumption in section 2.5.2, where we derive results for a linear demand with variable markups.

Assume that $\mu$ is sufficiently large such that all payment forms always imply positive profits, that is $\mu>\frac{1+r_{b}}{\tilde{\lambda}^{*}}$ and $\mu>\frac{1+r_{b}^{*}}{\tilde{\lambda}}$. Trade credit is then preferred over cash in advance if:

$$
\frac{\Delta \Pi_{S}}{C}=\tilde{\lambda}^{*} \mu-\left(1+r_{b}\right)-\left(1+r_{d}\right)\left(\frac{\tilde{\lambda}}{1+r_{b}^{*}} \mu-1\right)>0,
$$

where $\Delta \Pi_{S} \equiv \mathrm{E}\left[\Pi_{S}^{T C}\right]-\mathrm{E}\left[\Pi_{R S}^{C I A}\right]$. 


\subsection{Trade Credit and Markups}

Taking the derivative of equation (4) with respect to $\mu$ and rearranging delivers:

$$
\left(1+r_{b}^{*}\right) \tilde{\lambda}^{*}-\left(1+r_{d}\right) \tilde{\lambda}>0
$$

The condition is quite weak. As long as the buyer's borrowing rate is above the seller's deposit rate and enforcement is not too different for buyers and sellers, trade credit becomes more attractive when the markup goes up. The following Proposition summarizes our results on trade credit and markups:

\section{Proposition 1 (Trade Credit and Markups)}

Suppose $\left(1+r_{b}^{*}\right) \tilde{\lambda}^{*}>\left(1+r_{d}\right) \tilde{\lambda}$. Then:

i) The use of trade credit increases with the markup $\mu$.

ii) This effect increases with $r_{b}^{*}$ and $\lambda^{*}$ and decreases with $r_{d}$ and $\lambda$.

Proof. Follows from equation (5)

Part ii) of Proposition 1 presents additional predictions to test the mechanism explaining trade credit use: The effect of the markup should be stronger when the destination country's borrowing rate and enforcement are higher, and when the source country's deposit rate and enforcement are lower. The additional results on the interest rates are intuitive. The difference in borrowing needs between trade credit and cash in advance only matters if there is a positive difference between the borrowing rate and the deposit rate. Naturally, this effect is larger, the larger this interest rate difference.

Now, consider the symmetric case where the buyer and the seller face the same interest rates and enforcement frictions (e.g., because the buyer and the seller are in the same country).

\section{Corollary 1}

Suppose the buyer and the seller face the same financing costs and enforcement frictions, and the borrowing rate is above the deposit rate, $r_{b}>r_{d}$. Then, firms should always use trade credit.

Proof. Follows directly from equation (4).

That is, the financing friction combined with a positive markup provides a clear rationale for the dominance of trade credit in firm-to-firm transactions, especially in the domestic context where firms face more similar frictions. Then, trade credit dominates because it minimizes borrowing from financial institutions and thereby financial intermediation costs. 


\subsection{Trade Credit and Repeated Interactions}

Consider now the case where a buyer and a seller interact repeatedly. Importantly, we assume that sellers cannot offer dynamic contracts to solve the commitment problem, for example, by implementing a trigger strategy under trade credit. ${ }^{19}$ However, as they interact repeatedly, firms update their belief about each other's reliability. Assume that with every successful transaction, a firm's belief about its trading partner's reliability improves. That is, assume that $\partial \eta_{k} / \partial k>0\left(\partial \eta_{k}^{*} / \partial k>0\right)$, where $k$ is the number of previous interactions and $\eta_{k}\left(\eta_{k}^{*}\right)$ is the probability that a seller (buyer) is reliable after $k$ interactions. Note that the dynamics do not necessarily have to arise from learning about the trading partner's reliability. Any dynamic process that raises the expected reliability of the trading partner over time would generate similar predictions. For example, firms may be more willing to fulfill their contracts due to relationship-specific investments or learning-by-doing. In appendix B.3, we provide one example of Bayesian learning that can micro-found the assumed learning dynamics. ${ }^{20}$

We allow the speed of learning to differ between buyers and sellers, with $\eta_{k}^{*}$ and $\eta_{k}$, representing the belief about the probability that a buyer or seller is reliable after $k$ interactions, respectively. The optimal payment choice is then determined by:

$$
\frac{\Delta \Pi_{S}}{C}=\tilde{\lambda}_{k}^{*} \mu-\left(1+r_{b}\right)-\left(1+r_{d}\right)\left(\frac{\tilde{\lambda}_{k}}{1+r_{b}^{*}} \mu-1\right) .
$$

where $\tilde{\lambda}_{k}$ and $\tilde{\lambda}_{k}^{*}$ are increasing in the number of previous interactions $k$, as $\eta$ and $\eta^{*}$ increase. Taking the derivative with respect to $k$ delivers:

$$
\frac{\partial\left(\Delta \Pi_{S} / C\right)}{\partial k}=\mu\left(\left(1-\lambda^{*}\right) \frac{\partial \eta_{k}^{*}}{\partial k}-\frac{1+r_{d}}{1+r_{b}^{*}}(1-\lambda) \frac{\partial \eta_{k}}{\partial k}\right) .
$$

This derivative is positive if $\frac{\partial \eta_{k}^{*}}{\partial k}>\frac{1+r_{d}}{1+r_{b}^{*}} \frac{1-\lambda}{1-\lambda^{*}} \frac{\partial \eta_{k}}{\partial k}$. If learning about the buyer is sufficiently fast relative to learning about the seller, then trade credit becomes more attractive as two firms repeatedly trade with each other. Learning about the buyer is key because the commitment problem under trade credit only depends on the reliability of the buyer $\left(\eta_{k}^{*}\right)$. Thus, for the financial cost advantage of trade credit to dominate over time, the commitment problem under

\footnotetext{
${ }^{19}$ See Schmidt-Eisenlohr (2011), Olsen (2016), and Fischer (2020) for an analysis of optimal dynamic contracts in this environment.

${ }^{20}$ The micro-foundation in appendix B.3 is also used in Araujo and Ornelas (2007), Antràs and Foley (2015), Macchiavello and Morjaria (2015) and Monarch and Schmidt-Eisenlohr (2016).
} 
trade credit needs to decline through learning about the buyer. Specifically, learning about the buyer cannot be too slow relative to learning about the seller, as the latter makes cash in advance more attractive. Importantly, the condition implied by (6) allows for some asymmetry in the speed of learning, that is trade credit use increases with relationship age even if learning about the seller is a bit faster (as long as $\left.r_{b}^{*}>r_{d}\right) .{ }^{21}$ This result is summarized in Proposition 2 .

\section{Proposition 2 (Trade Credit and Learning)}

Suppose learning about the buyer is sufficiently fast, that is: $\frac{\partial \eta_{k}^{*}}{\partial k}>\frac{1+r_{d}}{1+r_{b}^{*}} \frac{1-\lambda}{1-\lambda^{*}} \frac{\partial \eta_{k}}{\partial k}$. Then, payment is more likely on trade credit terms, the longer the two firms have traded.

Proof. Follows directly from equation (6).

The proposition is quite intuitive. The longer two firms trade with each other, the more likely they will fulfill their contracts. The key advantage of trade credit is that it saves on financial costs as compared to cash in advance. Through learning, contract enforcement becomes less of an issue and financing costs differences matter more for the contract choice. Therefore, as firms learn that their trading partners are reliable, they tend to favor trade credit over cash in advance.

\subsection{Relationship Length and Markups}

How do relationship length and markups interact? Recall that the model features two frictions: An enforcement problem and a financial intermediation costs. These two frictions lead to striking dynamic predictions that we derive formally below. First, the role of relationship lengths for the payment terms choice decreases over time, as firms learn about their trading partners and enforcement becomes less of a concern. Second, as enforcement frictions decline, the financial friction becomes relatively more important, making markups more central for the payment choice in older relationships.

Trade Credit and a Declining Speed of Learning Earlier in equation (6), we derived the change in the relative profits between trade credit and cash in advance in relationship age, $k$.

\footnotetext{
${ }^{21}$ The speed of learning could be a function of the payment terms. In particular, there could be more learning about the seller under cash in advance and more learning about the buyer under trade credit, due to the asymmetry in the commitment problem. For tractability, we focus on the case where learning is independent of the payment terms. The key assumption is that there is learning in both directions and that the speed of learning is not too dissimilar.
} 
Now, taking the second derivative of equation (6) with respect to relationship length $k$ delivers:

$$
\frac{\partial^{2}\left(\Delta \Pi_{S} / C\right)}{\partial k^{2}}=\mu\left(\left(1-\lambda^{*}\right) \frac{\partial^{2} \eta_{k}^{*}}{\partial k^{2}}-\frac{1+r_{d}}{1+r_{b}^{*}}(1-\lambda) \frac{\partial^{2} \eta_{k}}{\partial k^{2}}\right)
$$

This derivative is negative if: $-\frac{\partial^{2} \eta_{k}^{*}}{\partial k^{2}}>-\frac{1+r_{d}}{1+r_{b}^{*}} \frac{1-\lambda}{1-\lambda^{*}} \frac{\partial^{2} \eta_{k}}{\partial k^{2}}$. Now, assume that the speed of learning is decreasing over time. ${ }^{22}$ And consider the special case where the speed of learning is symmetric, so that: $\frac{\partial^{2} \eta_{k}^{*}}{\partial k^{2}}=\frac{\partial^{2} \eta_{k}}{\partial k^{2}}$. Then, the above condition simplifies to: $\left(1-\lambda^{*}\right)>\frac{1+r_{d}}{1+r_{b}^{*}}(1-\lambda)$. In this case, the effect of repeated interactions on the trade credit choice declines over time as long as countries are not too different and $r_{b}^{*}>r_{d}$.

Trade Credit, Learning, and Markups We now derive a key prediction of our model, namely that there is an interaction between the markup and the number of repeated transactions between the buyer and the seller. To see this, we start again from equation (6). Taking the cross-derivative with respect to the markup $\mu$ delivers:

$$
\frac{\partial^{2}\left(\Delta \Pi_{S} / C\right)}{\partial k \partial \mu}=\left(\left(1-\lambda^{*}\right) \frac{\partial \eta_{k}^{*}}{\partial k}-\frac{1+r_{d}}{1+r_{b}^{*}}(1-\lambda) \frac{\partial \eta_{k}}{\partial k}\right),
$$

which is positive if: $\frac{\partial \eta_{k}^{*}}{\partial k}>\frac{1+r_{d}}{1+r_{b}^{*}} \frac{1-\lambda}{1-\lambda^{*}} \frac{\partial \eta_{k}}{\partial k}$. The following proposition summarizes our results:

\section{Proposition 3 (Repeated Interactions, Learning, and Markups)}

1. Suppose the speed of learning declines in the length of a relationship and learning speeds are not too different $\left(-\frac{\partial^{2} \eta_{k}^{*}}{\partial k^{2}}>-\frac{1+r_{d}}{1+r_{b}^{*}} \frac{1-\lambda}{1-\lambda^{*}} \frac{\partial^{2} \eta_{k}}{\partial k^{2}}\right)$. Then, the effect of learning on the payment choice declines in the number of interactions $k$.

2. Suppose learning speeds are not too different $\left(\frac{\partial \eta_{k}^{*}}{\partial k}>\frac{1+r_{d}}{1+r_{b}^{*}} \frac{1-\lambda}{1-\lambda^{*}} \frac{\partial \eta_{k}}{\partial k}\right)$. Then, the effect of the markup on the payment choice increases with the number of interactions $k$.

Proof. Follows directly from equations (7) and (8).

Proposition 3 formalizes the intuition provided at the beginning of this section. As firms continually trade with each other, learning becomes less important and the financial frictions and thereby markups become more important for choosing the payment terms. In the limit, when firms have perfectly learned the type of their trading partners, the payment choice only depends on financial costs and thus trade credit tends to dominate.

\footnotetext{
${ }^{22} \mathrm{~A}$ decreasing speed of learning is a feature of most learning models. See appendix B.3 for details on how to micro found this assumption with a model of Bayesian learning.
} 


\subsection{Model Extensions}

\subsubsection{Introducing Bargaining}

So far, we derived results assuming that the seller has all bargaining power. To generalize the results, we now extend the model to allow for differing bargaining weights between the buyer and the seller. As there is private information about the type of the buyer and the seller, we use the Neutral Bargaining Solution proposed by Myerson (1984), which generalizes Nash Bargaining to the case of private information. The basic idea is that under the Neutral Bargaining Solution, the two parties play a random dictator game, where they must respect constraints from asymmetric information, as the other player can always reject the offer of the dictator. Specifically, this implies that a buyer or seller cannot propose a solution that violates the participation constraint of the other firm. As shown by Balkenborg et al. (2006), this solution can be generalized to arbitrary bargaining weights be letting the two parties be the dictator in the game with the probability given by the bargaining weight. Let $\theta$ denote the bargaining weight of the seller.

Trade Credit Recall that expected profits for reliable buyers and all sellers with trade credit are $\mathrm{E}\left[\Pi_{S}^{T C}\right]=\tilde{\lambda}^{*} P^{T C}-\left(1+r_{b}\right) C$ and $\mathrm{E}\left[\Pi_{R B}^{T C}\right]=R-P^{T C}$, respectively. As shown before, if the seller has all bargaining power, she sets $P_{S}^{T C}=R$. In contrast, if the buyer has all bargaining power, she sets the payment so that a reliable seller is indifferent, that is $P_{B}^{T C}=\frac{1+r_{b}}{\tilde{\lambda}^{*}} C$. Combining the two solutions of the dictator game, we calculate the payment under trade credit based on the Neutral Bargaining Solution as:

$$
P_{N}^{T C}=\theta P_{S}^{T C}+(1-\theta) P_{B}^{T C}=\frac{\theta \tilde{\lambda}^{*} R+(1-\theta)\left(1+r_{b}\right) C}{\tilde{\lambda}^{*}}
$$

Expected profits of a seller and reliable buyer are then given by:

$$
\begin{aligned}
\mathrm{E}\left[\Pi_{S}^{T C}\right] & =\theta\left(\tilde{\lambda}^{*} R-\left(1+r_{b}\right) c\right) \\
\mathrm{E}\left[\Pi_{R B}^{T C}\right] & =\frac{1}{\tilde{\lambda}^{*}}(1-\theta)\left(\tilde{\lambda}^{*} R-\left(1+r_{b}\right) c\right) .
\end{aligned}
$$

Cash in Advance Recall that expected profits for all buyers and reliable sellers under cash in advance are $\mathrm{E}\left[\Pi_{R S}^{C I A}\right]=\left(1+r_{d}\right)\left(P^{C I A}-C\right)$ and $\mathrm{E}\left[\Pi_{B}^{C I A}\right]=\tilde{\lambda} R-\left(1+r_{b}^{*}\right) P^{C I A}$, respectively. As shown before, the seller would choose $P_{S}^{C I A}=\frac{\tilde{\lambda}}{1+r_{b}^{*}} R$. If the buyer has all bargaining power, 
she makes the reliable seller indifferent by setting $P_{B}^{C I A}=C$. Combining the two solutions of the dictator game, we calculate the payment under cash in advance based on the Neutral Bargaining Solution as:

$$
P_{N}^{C I A}=\theta P_{S}^{C I A}+(1-\theta) P_{B}^{C I A}=\frac{\theta \tilde{\lambda} R+(1-\theta)\left(1+r_{b}^{*}\right) C}{1+r_{b}^{*}} .
$$

This implies expected profits for a reliable seller and any buyer of:

$$
\begin{gathered}
\mathrm{E}\left[\Pi_{R S}^{C I A}\right]=\theta \frac{1+r_{d}}{1+r_{b}^{*}}\left(\tilde{\lambda} R-\left(1+r_{b}^{*}\right) C\right), \\
\mathrm{E}\left[\Pi_{B}^{C I A}\right]=(1-\theta)\left(\tilde{\lambda} R-\left(1+r_{b}^{*}\right) C\right) .
\end{gathered}
$$

Optimal Contract In the following, we derive the optimal contract under the Neutral Bargaining Solution. For this, we assume that the firm that plays the dictator not only chooses the size of the payment but also the contract. The optimal contract is then a mixed strategy between the choice of the buyer and the choice of the seller with weights $\theta$ and $1-\theta$, respectively. As in the baseline model, we assume that conditions are such that it is always optimal for unreliable firms to imitate the behavior of reliable firms and for all firms to offer contracts that are acceptable to both types of firms (See Appendices B.2 and B.4 for details).

We now need to look separately at the payment choices of both the seller and the buyer. Combining equations (9) and (11) delivers the optimal choice of a reliable. This condition is, of course, the same condition we derived for the baseline model where the seller had all bargaining power, equation (3). Now, combining equations (10) and (12) delivers the optimal choice of a reliable buyer:

$$
\mathrm{E}\left[\Pi_{R B}^{T C}\right]>\mathrm{E}\left[\Pi_{B}^{C I A}\right] \Leftrightarrow R-\frac{1+r_{b}}{\tilde{\lambda}^{*}} C-\left(\tilde{\lambda} R-\left(1+r_{b}^{*}\right) C\right)>0 .
$$

Replacing $R=\mu C$ and taking the derivative of equation (13) with respect to $\mu$ gives:

$$
\frac{\partial\left(\Delta \Pi_{B} / C\right)}{\partial \mu}=1-\tilde{\lambda}
$$

where $\Delta \Pi_{B} \equiv \mathrm{E}\left[\Pi_{R B}^{T C}\right]-\mathrm{E}\left[\Pi_{B}^{C I A}\right]$. For the seller choice, the corresponding derivative $\left(\frac{\partial\left(\Delta \Pi_{S} / C\right)}{\partial \mu}\right)$ is unchanged from the baseline and given by equation (5), where the preference for trade credit increases with the markup as long as countries are not too different and $r_{b}^{*}>r_{d}$. Interestingly, 
equation (14) shows that the buyer also prefers trade credit more as the markup increases. This reflects a different mechanism, however. With trade credit, the buyer always obtains the goods, whereas under cash in advance, goods only arrive with probability $\tilde{\lambda}$. The difference $1-\tilde{\lambda}$ therefore reflects the lost business for the buyer under cash in advance. The buyer cannot offset this loss in business by paying an even lower cash in advance price because that price is bound below by the production cost $C$, as a payment below production cost would make a reliable seller reject the offer. As buyers learn about sellers and $\tilde{\lambda}$ converges to one, this markup effect vanishes. This contrasts with Proposition 3 on the optimal decision of sellers, where markups become more important over time. In the following we summarize our results under the Neutral Bargaining Solution:

\section{Corollary 2 (Payment Choice and Bargaining Power)}

Suppose the seller has some bargaining power $(\theta \in(0,1])$. Then all predictions in Proposition 1 hold for the case where both firms have bargaining power. That is:

i) If $\left(1+r_{b}^{*}\right) \tilde{\lambda}^{*}>\left(1+r_{d}\right) \tilde{\lambda}$, then the use of trade credit increases with the markup $\mu$.

ii) This effect increases with $r_{b}^{*}$ and $\lambda^{*}$ and decreases with $r_{d}$ and $\lambda$.

Proof. Follows directly from equations (5) and (14), and from taking the respective derivatives of these equations with respect to $\lambda, \lambda^{*}, r_{d}$, and $r_{b}^{*}$.

To summarize, introducing bargaining power for both sellers and buyers does not affect our main result on trade credit and markups. The financial friction channel is active as long as the seller has some bargaining power that allows the seller to charge a positive markup over marginal costs to the buyer.

\subsubsection{Variable Markups}

We now introduce variable markups to the model. This is a key extension, as it micro-founds the instrumental-variable approach employed later in the paper, where we instrument markups with productivity estimates. As the main purpose of this section is to convey the mechanism, we assume a straightforward linear demand, that would follow, for example, from a demand system as in Melitz and Ottaviano (2008). However, the below results do not depend on this specific modeling choice for variable markups. Assume that demand takes the form $Q(p)=1-p$.

Expected profits under the two payment forms can be represented by the general form $\Pi=\alpha p Q(p)-\beta c Q(p)=(\alpha p-\beta c)(1-p)$. Taking the derivative with respect to $p$ and solving 
the first-order condition delivers $p=\frac{1}{2}+\frac{\beta}{\alpha} \frac{c}{2}$. Recall that under trade credit, the payment to the seller is $P^{T C}=R$, while under cash in advance it is $P^{C I A}=\frac{\tilde{\lambda}}{1+r_{b}^{*}} R .^{23}$ This implies the following markups $(\mu=P / Q c)$ between the price paid by the buyer and the production cost of the seller:

$$
\begin{aligned}
\mu^{T C} & =\frac{1}{2 c}+\frac{1+r_{b}}{\tilde{\lambda}^{*}} \frac{1}{2} \\
\mu^{C I A} & =\frac{\tilde{\lambda}}{1+r_{b}^{*}}\left(\frac{1}{2 c}+\frac{1+r_{b}^{*}}{\tilde{\lambda}} \frac{1}{2}\right) .
\end{aligned}
$$

It is easy to see that markups decrease (increase) in the marginal cost (productivity). ${ }^{24}$ We can derive the following difference in expected profits between trade credit and cash in advance:

$$
\Delta \Pi=\tilde{\lambda}^{*}\left[\frac{1}{2}-\frac{1+r_{b}}{\tilde{\lambda}^{*}} \frac{c}{2}\right]^{2}-\frac{1+r_{d}}{1+r_{b}^{*}} \tilde{\lambda}\left[\frac{1}{2}-\frac{1+r_{b}^{*}}{\tilde{\lambda}} \frac{c}{2}\right]^{2}
$$

Now, focusing on the symmetric case and plugging in the markups into the profits delivers:

$$
\Delta \Pi=\tilde{\lambda}\left[1-\frac{1+r_{d}}{1+r_{b}}\right]\left[\left(\mu^{T C}-\frac{1+r_{b}}{\tilde{\lambda}}\right) c\right]^{2}
$$

First, note that this difference is positive as long as the borrowing rate exceeds the deposit rate, $r_{b}>r_{d}$. Taking the derivative with respect to $\mathrm{c}$ and plugging in for $\frac{\partial \mu^{T C}}{\partial c}$ :

$$
\frac{\partial \Delta \Pi}{\partial c}=-\frac{1+r_{b}}{2}\left[1-\frac{1+r_{d}}{1+r_{b}}\right]\left[\left(\mu^{T C}-\frac{1+r_{b}}{\tilde{\lambda}}\right) c\right]<0 .
$$

These results are summarized in Proposition 4.

\section{Proposition 4 (Trade Credit and Variable Markups)}

Suppose the buyer and the seller face the same financial costs and enforcement frictions, the borrowing rate is above the deposit rate, $r_{b}>r_{d}$, and firms face a linear demand. Then:

1. The markup decreases with the marginal cost of production c.

\footnotetext{
${ }^{23}$ To have non-negative quantities, we impose the restriction that the unit production cost of the buyer, $c$, has to be lower or equal to $\lambda /\left(1+r_{b}\right)$. 24

$$
\frac{\partial \mu^{T C}}{\partial c}=-\frac{1}{2 c^{2}}<0 ; \quad \frac{\partial \mu^{C I A}}{\partial c}=-\frac{\tilde{\lambda}}{1+r_{b}^{*}} \frac{1}{2 c^{2}}<0 .
$$
}


2. By decreasing the markup, an increase in the marginal cost of production makes trade credit less attractive relative to cash in advance.

Proof. Follows directly from taking the derivatives of equations (15) and (16) with respect to $c$, and from equation (17).

\subsubsection{Trade Credit, Learning, and Enforcement}

Does the strength of a country's institutions affect the relationship between repeated interactions and trade credit? This would be intuitive as learning works as a substitute for imperfect contract enforcement in the model. In particular, if contracts were perfectly enforceable, learning would not matter. To check for this mechanism in the model, start with equation (6) and take the cross-derivatives with respect to $\lambda$ and $\lambda^{*}$ to get:

$$
\begin{aligned}
& \frac{\partial^{2}(\Delta \Pi / C)}{\partial k \partial \lambda}=\mu(\underbrace{\frac{\partial \eta_{k}}{\partial k}}_{\text {Direct Effect }} \underbrace{-(1-\lambda) \frac{\partial^{2} \eta_{k}}{\partial k \partial \lambda}}_{\text {Indirect Effect }}) \frac{1+r_{d}}{1+r_{b}^{*}}, \\
& \frac{\partial^{2}(\Delta \Pi / C)}{\partial k \partial \lambda^{*}}=\mu(\underbrace{-\frac{\partial \eta_{k}^{*}}{\partial k}}_{\text {Direct Effect }} \underbrace{+\left(1-\lambda^{*}\right) \frac{\partial^{2} \eta_{k}^{*}}{\partial k \partial \lambda^{*}}}_{\text {Indirect Effect }}) .
\end{aligned}
$$

There are two effects. First, a direct effect: With better enforcement in the seller (buyer) country, learning has a stronger (weaker) effect on the payment choice. To understand the intuition for the direct effect, recall that trade credit becomes more attractive as the seller learns that the buyer is more reliable (as trade credit creates the risk that the buyer does not pay). Stronger enforcement in the seller (buyer) country reduces the importance of learning about the seller (buyer), which makes learning more about the buyer (seller) and strengthens (weakens) the positive effect of learning on trade credit.

The second effect depends on how the speed of learning changes with enforcement $\left(\frac{\partial^{2} \eta_{k}}{\partial k \partial \lambda}\right.$ and $\left.\frac{\partial^{2} \eta_{k}^{*}}{\partial k \partial^{*}}\right)$. Typically, with weaker enforcement, learning is faster initially but slower later on, such that the sign of the cross-derivative changes in $k$. However, one would typically expect the direct effect to dominate the indirect effect, which we put as a condition into the proposition below.

\section{Proposition 5}

Suppose learning speeds are not too different across countries with different levels of enforcement $\left((1-\lambda) \frac{\partial^{2} \eta_{k}}{\partial k \partial \lambda}<\frac{\partial \eta_{k}}{\partial k}\right.$ and $\left.\left(1-\lambda^{*}\right) \frac{\partial^{2} \eta_{k}^{*}}{\partial k \partial \lambda^{*}}<\frac{\partial \eta_{k}^{*}}{\partial k}\right)$. Then, the effect of learning on trade credit increases (decreases) in the strength of contract enforcement in the seller (buyer) country. 
Proof. Follows directly from equations (18) and (19).

\subsubsection{Trade Credit, Learning, and Product Complexity}

In a final extension, we look at the role of product characteristics, in particular, product complexity. The basic idea is that contract enforcement is harder for more complex products as courts have a harder time to verify a successful transaction. For example, quality may be more difficult to verify for more complex products

Following Hoefele et al. (2016), assume that product complexity is captured by parameter $\gamma \in[0,1]$, where a higher $\gamma$ represents a more complex product. Assume further that a contract now gets enforced exogenously with probability $\lambda^{\gamma}$, so contracts for more complex products are harder to enforce. Focusing on the symmetric case, the optimal decision becomes:

$$
\frac{\Delta \Pi}{C}=\tilde{\lambda}_{k, B}(\gamma) \mu-\left(1+r_{b}\right)-\left(1+r_{d}\right)\left(\frac{\tilde{\lambda}_{k, S}(\gamma)}{1+r_{b}} \mu-1\right)
$$

with $\tilde{\lambda}_{k, i}(\gamma)=\eta_{k, i}+\left(1-\eta_{k, i}\right) \lambda^{\gamma}$. Taking the derivative with respect to $k$ delivers:

$$
\frac{\partial(\Delta \Pi / C)}{\partial k}=\mu\left(1-\lambda^{\gamma}\right)\left[\frac{\partial \eta_{k, B}}{\partial k}-\frac{1+r_{d}}{1+r_{b}} \frac{\partial \eta_{k, S}}{\partial k}\right] .
$$

Taking the derivative with respect to $\gamma$ and rearranging delivers:

$$
\frac{\partial^{2}(\Delta \Pi / C)}{\partial k \partial \gamma}=-\mu \lambda^{\gamma}\left[\frac{\partial \eta_{k, B}}{\partial k}-\frac{1+r_{d}}{1+r_{b}} \frac{\partial \eta_{k, S}}{\partial k}\right] \ln (\lambda) .
$$

which is greater or equal to zero as $\ln \lambda \leq 0$. That is, the effect of learning on the difference between trade credit and cash in advance is stronger for more complex products (higher $\gamma$ ). This is summarized in the following Proposition:

\section{Proposition 6}

Suppose the buyer and the seller face the same financial costs and enforcement frictions, and

learning speeds are not too different $\left(\frac{\partial \eta_{k}^{*}}{\partial k}>\frac{1+r_{d}}{1+r_{b}^{*}} \frac{1-\lambda}{1-\lambda^{*}} \frac{\partial \eta_{k}}{\partial k}\right)$, and enforcement is imperfect $(\lambda<1)$. Then, trade credit use increases with relationship length, and the strength of this effect increases with the complexity of the product that is traded.

Proof. Follows directly from equations (20) and (21).

Proposition 6 is quite intuitive: Contracts for more complex products are harder to enforce and 
hence learning, which reduces the need for contract enforcement, has a stronger effect on firms' payment choices.

\section{Empirical Approach}

This section presents the empirical methodology we follow for testing the predictions of the theoretical model. We begin presenting the specifications we use to test predictions related to the role of markups. Then, we discuss the specifications we use to test predictions related to relationship length.

\subsection{Trade Credit and Markups}

To test Proposition 1 on the relationship between trade credit and markups, we estimate the following baseline regression:

$$
\rho_{i p j y}=\beta_{1} \ln \left(\mu_{i p y}\right)+\beta_{2} \ln \left(L_{i y}\right)+\delta_{i}+\delta_{p}+\delta_{j y}+\epsilon_{i p j y},
$$

where $\rho_{i p j y}$ denotes the share of trade credit in total exports by firm $i$ of product $p$ to country $j$ in year $y . \mu_{i p y}$ is the firm-product level markup. The model predicts that $\beta_{1}>0$, that is, all else equal, firms with larger markups should sell more on trade credit. The baseline specification includes firm fixed-effects $\left(\delta_{i}\right)$ to control for time-invariant factors affecting firms' trade credit share, and product-fixed effects $\left(\delta_{p}\right)$ to account for differences in product characteristics leading to dispersion in trade credit use. In addition, we include destination-year fixed effects $\left(\delta_{j y}\right)$ to account for country-level characteristics directly affecting trade-credit choice for all firms, such as the strength of contract enforcement in the destination country (Antràs and Foley, 2015). Finally, we include firm employment $\left(L_{i y}\right)$ to control for the effect of differences in firm size on trade credit use.

Markups Estimation. We construct a measure of markups following De Loecker et al. (2016). This methodology requires minimal working assumptions, is flexible with respect to the underlying demand system, and only requires production data. ${ }^{25}$ The main insight of this methodology is that price-cost markup of a firm-product can be computed as the ratio between

\footnotetext{
${ }^{25}$ The main assumptions are that firms minimize costs for each product $p$, and that at least one input production input is fully flexible.
} 
two elements: (i) The output elasticity of product $p$ with respect to any flexible input $V\left(\theta_{i p y}^{V}\right)$, and (ii) the expenditure share of the flexible input $V$ (relative to the sales of product $p ; s_{i p y}^{V}$ ). We briefly explain how we compute each of this elements next, and relegate technical details to appendix $\mathrm{C}$.

To estimate the production function coefficients, we specify for each product $p$ a CobbDouglas production function, with labor, capital, and materials as production inputs. ${ }^{26}$ We measure output in terms of physical units, and deflate materials expenditure with a firm-specific input price index. ${ }^{27}$ The approach we follow to identify the production function coefficients in multi-product firms follows De Loecker et al. (2016), who assume that products are produced with the same technology in single- and multi-product firms. ${ }^{28}$ Hence, we identify the production function for all firms-products using the subset of single-product firms. To estimate the coefficients, we follow the methodology proposed by Ackerberg et al. (2015) to control for the endogeneity of firms' inputs choice. ${ }^{29}$

The second component needed to compute markups is the expenditure share, which is observed at the firm-level. To estimate this element for products within a firm, we follow GarciaMarin and Voigtländer (2019) and proxy for product-specific input use assuming that inputs are used approximately in proportion to overall variable cost shares. ${ }^{30}$ Finally, we compute the expenditure share dividing the value of material inputs by product-specific revenues, which are observed in the data. Table C.1 in the appendix provides summary statistics for markups, aggregated at the 2-digit level.

Instrumental Variable Estimation One concern for the estimation of (22) through OLS is that markups are endogenous. In our framework, exporters charge higher prices when using trade credit, because they pass financial costs to the buyers and require compensation for

\footnotetext{
${ }^{26}$ As we show in the appendix table E.2, our results are not sensitive to the use of the more flexible Translog production function.

${ }^{27}$ See appendix $\mathrm{C}$ for details. Using output and inputs in terms of physical units avoids the occurrence of input and output price biases (see De Loecker and Goldberg, 2014, for details).

${ }^{28}$ The main limitation of this approach is that it restricts the existence of economies of scope on the production side. Nevertheless, as we discuss in the robustness checks section, our main results also hold when using average product margins (which are directly observed in our data) or when using the sample of single-product firms (which are not subject to this criticism).

${ }^{29}$ In addition, we implement the correction suggested by De Loecker (2013), to allow past exporting and investment decisions to affect firms' productivity, and include the probability of remaining single-product to correct for the bias that results from firm switching non-randomly from single to multi-product production (see De Loecker et al., 2016, for details).

${ }^{30}$ For this, we take advantage of the fact that ENIA provides information on total variable costs (labor cost and materials) for each product produced by the firms.
} 
the risk of non-payment by the buyer. We address this endogeneity concern by implementing an instrumental variable strategy, building on the insights of section 2.5.2. According to proposition 4, more efficient firms charge higher markups. To the extent that the efficiency of a firm-product does not increase the attractiveness of trade credit other than through its effect on the firm-product markup, we can use firm-product productivity as an instrument for markups. ${ }^{31}$ By using physical productivity as an instrument for markups, our methodology tackles the endogeneity of markups in two ways: First, by constructing firm-product specific markups, we shut down all variation across destinations. This addresses the concern that firms charge higher average markups in destinations where they offer open-account contracts. Second, by exploiting only changes in markups that are due to differences in physical productivity, we address the concern that observed markups may reflect demand conditions.

In the first stage we predict firm-product markups based on firm-product physical total factor productivity (TFPQ):

$$
\ln \left(\mu_{i p y}\right)=\gamma_{1} \ln \left(T F P Q_{i p y}\right)+\gamma_{2} \ln \left(L_{i y}\right)+\alpha_{i}+\alpha_{p}+\alpha_{j y}+\varepsilon_{i p j y}
$$

where $T F P Q_{i p y}$ denotes physical productivity of product $p$ produced by firm $i$ in year $y, L_{i y}$ is total firm employment, and $\left\{\alpha_{i}, \alpha_{p}, \alpha_{j y}\right\}$ are firm, product and country-year fixed effects, respectively. ${ }^{32}$ In the second stage, we regress the share of trade credit value exported by firm $i$ shipping product $p$ to country $j$ in year $y, \rho_{i p j y}$, on predicted log markups, $\widehat{\ln \mu_{i p y}}$, firm employment, and fixed effects:

$$
\rho_{i p j y}=\beta_{1} \widehat{\ln \mu_{i p y}}+\beta_{2} \ln \left(L_{i y}\right)+\delta_{i}+\delta_{p}+\delta_{j y}+\epsilon_{i p j y}
$$

Interactions with Country Characteristics In a next step, we test the second part of Proposition 1 on the interaction between markups and country characteristics. For this, we modify the baseline specification (22), adding interaction terms between firm-product markups and the domestic deposit rate $\left(r_{d}\right)$, the foreign borrowing rate $\left(r_{b}^{*}\right)$, and contract enforcement

\footnotetext{
${ }^{31}$ Since all specifications control for firm fixed-effects, the exclusion restriction allows for differences in productivity (for example due to variation in managerial ability) to have a direct effect on trade credit choice as long as these differences are time-invariant.

${ }^{32}$ See appendix $\mathrm{C}$ for details on the estimation of the production function at the firm-product level.
} 
in the destination country $\left(\lambda^{*}\right)$ :

$$
\begin{aligned}
\rho_{i j p y} & =\beta_{1} \ln \left(\mu_{i p y}\right)+\beta_{2} \ln \left(\mu_{i p y}\right) r_{b, j y}^{*}+\beta_{3} \ln \left(\mu_{i p y}\right) r_{d, y} \\
& +\beta_{4} \ln \left(\mu_{i p y}\right) \lambda_{j y}^{*}+\delta_{i y}+\delta_{j y}+\delta_{p}+\epsilon_{i j p y}
\end{aligned}
$$

Proposition 1 predicts that $\beta_{2}>0, \beta_{3}<0$, and $\beta_{4}>0$ : The positive effect of markups increases with the destination-country borrowing rate, $r_{b}^{*}$, decreases with the source-country deposit rate, $r_{d}$, and increases with the destination-country enforcement, $\lambda^{*}$. A key advantage of the specification with interaction terms is that it allows including firm-year or firm-productyear fixed effects, representing an even stricter test for our theory.

\subsection{Trade Credit and Relationship Length}

Next, we test the second main prediction of the model. According to Proposition 2, the use of trade credit should increase in the length of the trading relationship. To test this prediction, we use transaction-level data, allowing us to include a highly disaggregated set of fixed effects, including firm-product-destination and firm-product-year fixed effects.

We define relationships as all interactions occurring within a firm-product with a particular destination. As we do not have a unique identifier for individual buyers, sales by an exporter of the same product to multiple buyers in the same destination are not captured as separate relationships. ${ }^{33}$ Importantly, the noise introduced through this data constraint should make it more difficult to find evidence for learning within relationships. Hence, if the data contained unique buyer identifiers, we would expect our learning results to be even stronger.

The learning mechanism should be more prominent at the beginning of relationships, as buyers and sellers learn if their counterpart is reliable or not. Consequently, we restrict the main analysis to the sample of 'new relationships' starting in 2003 or later. ${ }^{34}$ The main regression exploits within-relationship variation, and takes the following form:

$$
\rho_{i j p d}=\kappa_{1} \ln (\text { Rel. Length })_{i j p d}+\psi_{i p y}+\psi_{j y}+\psi_{i j p}+\nu_{i j p d}
$$

\footnotetext{
${ }^{33}$ Our approach is similar to Antràs and Foley (2015, pp. 859), who use export information for a single U.S. based exporter, and where an observation covers "the shipment of a product to a specific customer location."

${ }^{34}$ We have access to transaction-level data for the period 2001-2007. However, we can only identify the use of trade credit reliably for the period 2003-2007. This explains the shorter period in the analysis involving trade credit use.
} 
where the sub-indexes $d$ indicates days and $y$ years, respectively. (Rel. Length) $)_{i j p d}$ captures the length of a relationship, and is calculated as the cumulative number of interactions from the beginning of the relationship. Specification (26) controls for relationship fixed-effects $\left(\psi_{i j p}\right)$, firm-product-year fixed-effects $\left(\psi_{i p y}\right)$, and destination-year fixed-effects $\left(\psi_{j y}\right)$. Proposition 2 predicts that $\kappa_{1}>0$ : The use of trade credit should increase in the length of the relationship.

Interactions with Country and Product Characteristics When testing prediction for learning and contract enforcement, we modify specification (26), adding interactions between the length of the relationship and contract enforcement in the buyer's country:

$$
\begin{aligned}
\rho_{i j p d}= & \phi_{1} \ln (\text { Rel. Length })_{i j p d} \lambda_{\text {high }, j}^{*}+\phi_{2} \ln (\text { Rel. Length })_{i j p d} \lambda_{\text {low }, j}^{*} \\
& +\psi_{i p d}+\psi_{j y}+\psi_{i j p}+\nu_{i j p d}
\end{aligned}
$$

where $\lambda_{\text {high }, j}^{*}$ and low $\lambda_{\text {low }, j}^{*}$ are categorical variables from countries with country enforcement above and below the median value of contract enforcement, respectively. Proposition 5 predicts that $\phi_{1}<\phi_{2}$ : The effect of learning on trade credit use should be stronger in destinations with weaker contract enforcement.

Finally, when testing predictions for product complexity, we modify again specification (26), interacting $\ln (\text { Rel. Length) })_{i j p d}$ with categorical variables for homogeneous $\left(\operatorname{Homog}_{p}\right)$ an differentiated (Diff $p$ ) products, defined in terms of the liberal version of Rauch (1999) product's classification: $:^{35}$

$$
\begin{aligned}
\rho_{i j p d}= & \zeta_{1} \ln (\text { Rel. Length })_{i j p d} \operatorname{Homog}_{p}+\zeta_{2} \ln (\text { Rel. Length })_{i j p d} \text { Diff }_{p} \\
& +\psi_{i p d}+\psi_{j y}+\psi_{i j p}+\nu_{i j p d}
\end{aligned}
$$

Proposition 6 predicts that $\zeta_{2}>\zeta_{1}$, that is, the use of trade credit should increase by more with the length of a relationship for differentiated products.

\section{Data}

We use two primary datasets to test the main predictions of the model. Both datasets cover different pieces of information for the universe of Chilean manufacturing exporters over the

\footnotetext{
${ }^{35}$ In particular, we consider products that are traded on an organized exchange or that have a reference price as homogeneous.
} 
period 2003-2007. This section reviews the main features of the data, describes the sample of our analysis, and provides descriptive evidence on the nature of the data.

The first data source is the Chilean National Customs Service and provides transaction-level data for the universe of Chilean exports. The data is available for the 90 main destinations of Chilean exports, which account for over $99.7 \%$ of the value of overall national exports in our sample period. For each export transaction, the dataset details the identity of the exporter, the importing country, product description, and the 8-digit HS code to which the product belongs, the date of the transaction, the FOB value and volume of the merchandise, and the financing mode of the export transaction. The data allows to identify if each transaction was paid in advance (cash in advance - CIA), post-shipment (trade credit - TC), or with other modes (such as letters of credit or two-part contracts).

We complement the transaction-level data from customs with production-level data from the Encuesta Nacional Industrial Anual (Annual National Industrial Survey - ENIA). ENIA is collected by the Chilean National Statistical Agency (INE), and provides annual production information for the universe of Chilean manufacturing plants with 10 or more employees, according to the International Standard Industrial Classification (ISIC), revision 3. It surveys approximately 4,900 manufacturing plants per year, out of which $20 \%$ are exporters. ENIA provides standard micro-level information (e.g., sales, inputs expenditures, employment, investment), and detailed information for each good produced (sales value, production cost, number of units produced and sold), and inputs purchased by the firm (value and volume for each input purchased by the plant). Outputs and inputs products are defined according to Central Product Classification (CPC) at the 8-digit level, identifying 1,190 products over 2003-2007.36

We use two additional data sources to obtain information on the destination countries' characteristics. First, we collect information for the importing countries' deposit and lending rate, as well as for domestic inflation from the International Monetary Fund's International Financial Statistics. We use this data to construct real (ex-post) interest rates as the difference between the nominal rates and the realized inflation in the respective year. Second, we use the Rule of Law index constructed by the World Bank's World Government Indicator to proxy for the likelihood of contract enforcement in each country.

To ensure a consistent dataset, we follow several steps, including the deletion of observations that have missing, zero, or implausible variation in the values of any of the main variables.

\footnotetext{
${ }^{36}$ For example, CPC disaggregates the wine industry (ISIC 3132) into 4 different categories: "Sparkling wine", "Wine of fresh grapes", "Cider", and "Mosto".
} 
Appendix E provides details on these cleaning procedures, and on the matching procedure we applied to combine the information in the ENIA and Customs datasets. The final dataset consists of 608,588 firm-product-destinations-days observations, out of which approximately two-thirds correspond to relationships (defined at the firm-product-destination level) that started before 2003. The sample represents $80.5 \%$ of the value of Chilean (non-copper) exports over the period 2003-2007.

In the empirical analysis, we exploit the data at different levels of aggregation. When testing predictions for trade credit use and relationship length, we use the raw disaggregate data. However, when studying the relationship between trade credit and markups, we aggregate the transactions data at the annual frequency, the frequency at which we estimate markups. Table 1 provides summary statistics for the main variables.

[Table 1 here]

\section{Results}

In this section, we present the main empirical results. We begin with results on the relationship between markups and trade credit choice. Next, we explore how the length of trade relationships affects the payment choice. We then report additional results on the interaction between relationship length with the strength of contract enforcement, product complexity, and markups. Finally, we discuss our robustness analysis.

\subsection{Trade Credit and Markups}

Descriptive Evidence Before turning to the main econometric results, we present graphical evidence. Figure 2 shows evidence for our first main result that trade credit use increases with firm-product level markups, and that the effect is more substantial for high interest rate destinations. The figure shows a binscatter plot, where the average trade credit share in each bin - defined as the percent of export value financed through trade credit - is plotted against the average firm-product markup (in logarithm). For both variables, the plot is based on residuals after taking out country-year fixed effects. The left panel shows the data for destinations with borrowing rates that are above the median rate across years and destinations. In contrast, the right panel shows data for destinations with below-median borrowing rates.

[Figure 2 here] 
The figure shows a clear positive relationship between the trade credit share and markups. Moreover, as predicted in Proposition 1, the effect is stronger for destinations with relatively high borrowing rates. 37

Baseline Econometric Results. Table 2 presents our baseline results on trade credit use and markups. In line with Proposition 1 and the evidence presented in figure 2 above, the estimated coefficient for the markup has a positive sign and is highly significant across all specifications. Column 1 shows OLS results using the estimated markups. In columns 2 and 3, we use two alternative markup measures: First, the estimated markup when a firm-product is first observed in the sample (column 2). Second, the average estimated markup within firmproducts across all years (column 3). Note that, by construction, the specifications in columns 2 and 3 shut down within firm-product markup variation over time. This mitigates concerns about reverse causality, that is, the possibility that the positive correlation in the data arises from firms choosing trade credit for other reasons, which then raises markups. In both cases, the coefficient on markups is positive and highly significant despite the limited variation we exploit by fixing markups to their initial and average values, and including firm and product fixed effects.

\section{[Table 2 here]}

Instrumental Variable Results. We now move to our instrumental variable results. First, in column 4, we report results from a reduced form specification, where we directly regress trade credit use on TFPQ. The regression reveals a strong positive relationship between the two variables, providing direct support for Proposition 4: Firms extend more trade credit in products that they produce more efficiently (at a lower marginal cost).

Next, in column 5, we report the first stage results, where we instrument markups by TFPQ. The first stage works well, with an F-statistic substantially above the Stock-Yogo critical value of 16.4 for $10 \%$ maximal IV bias. Consistent with Proposition 4, the coefficient on TFPQ is positive and highly significant, implying that firms charge higher markups in products that they produce more efficiently. The magnitude of the first-stage coefficient implies that a ten percent increase in TFPQ is associated with an increase in markups by $0.52 \%$.

\footnotetext{
${ }^{37}$ Figures E.1 and E.2 in appendix E.1 replicate figure 2 for the share of transactions financed through cash in advance and letters of credit contracts. These figures suggest that firms increase the use of trade credit with markups at the expense of cash in advance contracts. The use of letters of credit contracts, in contrast, appears unresponsive to markups.
} 
Finally, in column 6, we show the second-stage results. The estimated coefficient on the trade credit share is positive and highly significant at the $1 \%$ level. The coefficient is also notably larger than the OLS coefficient in column 1, indicating that without instrumenting for the endogenous markups, results are biased towards zero. In quantitative terms, the estimated coefficient implies that an increase of one standard deviation in the firm-product markup (37.3 percent) increases the likelihood of using trade credit by 3.9 percentage points. The moderate magnitude of the effect should not be surprising when considering the pervasiveness of trade credit use: In our sample, about $90 \%$ of the transactions involve trade credit (see table 1). Consequently, firm-products with an already high trade credit share have less space to adjust, attenuating the effect of markups on trade credit. ${ }^{38}$

To summarize, the baseline results confirm the predictions in Proposition 1 and are robust to instrumenting markups by physical productivity at the firm-product level.

Interactions. Proposition 1, ii) predicts that the effect of markups on trade credit decreases with the seller's deposit rate and increases with the buyer's borrowing rate and the destination country's contract enforcement. Testing these predictions on the interaction terms constitutes an important check of the model for two reasons. First, the interactions between the markup and interest rates directly speak to the key mechanism of the model: Trade credit saves financing costs as it reduces total borrowing needs, and financial cost savings should be proportional to the product of the markup and the interest rate differential. Second, estimating a specification with interaction terms allows for the inclusion of a more complete set of fixed effects, which substantially reduces concerns of omitted variable bias. Table 3 present the results from estimating equation (25); we report OLS (columns 1 to 4) and 2SLS (columns 5 to 8) estimates. In all specifications, standard errors are clustered at the firm-destination level.

[Table 3 here]

Results in table 3 confirm the predictions of Proposition 1. Similar to the baseline estimates in table 2, 2SLS results yield strong first-stages and confirm findings for OLS results, with the 2SLS coefficients again being notably larger. Columns 1 and 5 show that the coefficient on the interaction term for the seller's deposit rate, $r_{d}$, is negative, and the coefficient on the interaction term for the buyer's borrowing rate, $r_{b}^{*}$ is positive (although only the latter is

\footnotetext{
${ }^{38}$ Table E.3 in the appendix shows that the estimated effects becomes even larger when taking the bounded nature of the trade credit share into account by using a Logit transformation. Then, the average effect of markups on trade credit is about double the size relative to the baseline specification.
} 
statistically significant). The insignificant coefficient for the seller's deposit rate, $r_{d}$, is not surprising, as there is only one seller country, Chile, in our data.

To gauge the quantitative relevance of these effects, consider two firms at the 25th (markup of 0.88 ) and 75th percentile (markup of 1.47) of the markup distribution, respectively. Based on the coefficient in column 5, a one-standard-deviation higher borrowing rate (4.5 percentage points) in the destination country then increases the share of trade credit by 2.53 percentage points for a firm with a markup at the 75 th percentile relative to a firm with a markup at the 25th percentile. Columns 2 and 6 present results on contract enforcement, using the destination country's rule of law index as a proxy for contract enforcement. As predicted by the theory, stronger enforcement abroad strengthens the relationship between the markup and trade credit provision. However, the interaction term is only significant for the 2SLS specification (column 6). Finally, columns 3, 4, 7, and 8 repeat the previous analysis, adding firm-product-year fixedeffects. Coefficients are very stable, suggesting that omitted variable bias at the firm-product level is not a concern here.

\subsection{Trade Credit and Repeated Interactions}

We now turn to evidence on trade credit use and buyer-seller relationships. According to proposition 2, trade credit use should increase with relationship length. To test this prediction, we use transaction-level data, defining relationships as all interactions occurring within a firmproduct in a particular destination.

Descriptive Evidence We begin by comparing the shares of different payment forms in the overall sample, with their shares in relationships that are new based on different criteria, which is shown in table 4 . Two broad patterns emerge from the data. First, trade credit is the dominant payment form. Almost 90 percent of the transactions are paid for this way. In contrast, about 5 percent of the transactions are paid cash in advance, and another 5 percent use letters of credit. Second, when focusing on new customers, the dominance of trade credit is notably dampened. Considering only the first transaction within a relationship, the share of trade credit declines to 79 percent, while 11 percent of transactions are paid cash in advance, and 7 percent use a letter of credit. The pattern is even stronger when focusing on the first transaction to a new export destination (third row in table 4), or on the first time a firm exports to any destination (fourth row). In these cases, the trade credit share for the first transactions 
declines to 75 and 66 percent, respectively. Cash in advance use increases up to 17 percent for the first export transaction of a firm, while the share of letters of credit slightly increases up to 9 percent, in the case of new exporters.

[Table 4 here]

This evidence is consistent with results in Antràs and Foley (2015) and suggests that exporters tend to extend more trade credit to old as opposed to new customers. Note, however, that this finding is more surprising than may be evident. Antràs and Foley (2015) studied the special case of a large U.S. food exporter. From the perspective of buyers, that firm is very reliable both because it is large and has been around for a long time and because it is located in the United States, a country with strong contract enforcement. In that particular case, it is natural to start with cash in advance (or letters of credit) and then move to trade credit over time.

Our empirical analysis shows that this pattern holds for a comprehensive sample of Chilean manufacturing exporters: Many relationships start on cash in advance terms and then move to trade credit, while switches in the other direction, from trade credit to cash in advance, are much less common. On this point, see also table 5 that reports the transition probabilities between payment forms. It shows that, a seller that asks for cash in advance or a letter of credit in a relationship today switches to trade credit for her next transaction with a probability of about 30 percent. In contrast, an exporter that currently offers trade credit will only ask for cash in advance or a letter of credit next time with probabilities of 3 percent and 2 percent, respectively.

[Table 5 here]

Importantly, this asymmetric pattern, where many more relationships switch towards trade credit than towards other payment forms, does not follow from the basic trade finance model as developed in Schmidt-Eisenlohr (2013) and Antràs and Foley (2015). It does, however, emerge naturally in the model with costly financial intermediation and positive markups derived in this paper. In our model, trade credit use rises in relationship length because learning makes enforcement less relevant and absent enforcement frictions trade credit tends to dominate. The 
latter aspect is absent from earlier theories, as they did not feature a financing cost advantage of trade credit. ${ }^{39}$

We now analyze the role of relationship length for the choice of trade credit more systematically. Figure 3 plots a binscatter diagram for the logarithm of relationship length — defined as the cumulative number of transactions occurring from the beginning of a relationship- and the average use of the three main payment terms. Panel A shows that the use of trade credit increases almost monotonically with the length of the relationship. Around 75 percent of first transactions are done on trade credit terms. This share increases with the age of a relationship until basically all sales are on trade credit terms. Panel B shows that the opposite occurs with the share of transactions that is paid cash in advance: This payment form is more commonly used at the beginning of a relationship and ceases to be used as a relationship ages. Finally, panel $\mathrm{C}$ shows that the use of letters of credit also decreases with relationship age, but to a much lesser extent than for cash in advance. This evidence is consistent with Proposition 2, suggesting that firms are more likely to use trade credit as they learn about the reliability of their trading partners.

[Figure 3 here]

Econometric Results. Table 6 presents regression results on the relationship between trade credit use and relationship length. All specifications control for firm-product-destination fixedeffects. Columns 2 and 3 sequentially add destination-year fixed-effects and firm-productyear fixed effects to control for country-specific and firm-product-specific time-varying shocks, respectively. As can be seen, across all specifications, the coefficient on relationship length is positive and statistically significant.

\section{[Table 6 here]}

One concern is that the results in columns 1 to 3 of table 6 may be affected by survival bias. This would bias results if, for example, short-lived relationships were less likely to rely on trade credit than longer-lasting relationships. Note, however, that columns 1 to 3 take care of

\footnotetext{
${ }^{39}$ Antràs and Foley (2015) studied one-sided learning by the seller about the buyer and assumed that there is no commitment problem for the seller (the big U.S. poultry exporter). A generalization of their setup to two-sided learning should, however, imply payment switches in both directions over time. If financing costs are lower in the buyer (seller) country, then firms should switch to cash in advance (trade credit) over time. Only the financing cost advantage of trade credit introduces the asymmetry that is necessary to generate a broad-based increase in the use of trade credit within relationships over time.
} 
this concern by including a firm-product-country fixed effect (the level at which a relationship is defined). The regressions thus only exploit within-relationship variation, implying that our results are not driven by composition effects. Column 4 provides further robustness on this point, re-estimating the specification in column 3, using a sample of the first twenty transactions in relationships with at least twenty trades. This sample - which we denote as 'balanced' is not subject to survival bias, because, by definition, all relations survive the entire sample period. The fact that the coefficient in column 4 is positive and has a similar magnitude as the one in column 3, where the full sample is used, suggests that survival bias does not affect our results.

Semi-parametric Estimation. We now employ a semi-parametric estimation to allow for a more flexible relationship between trade credit use and relationship length. We are particularly interested if most payment term changes take place early on in a relationship, as this would provide strong support to a learning interpretation.

Results are presented graphically in panel A of figure 4. As in table 6, the underlying estimation controls for firm-product-country and country-year fixed effects. Panel A shows the results for the non-parametric part of the regression, where we plot a kernel-weighted local polynomial on the number of transactions within a relationship. The figure shows a steep increase in the use of trade credit at the beginning of the relationship up until about the sixth transaction. After this point, trade credit use only increases slightly. This path is very consistent with a model of Bayesian learning (panel B), where learning is fastest early on in a relationship and then slows down. ${ }^{40}$ The semi-parametric result confirms the prediction in Proposition 3: If the speed of learning declines in the number of transactions, firms should switch more towards trade credit at the beginning of a relationship. The effect is quantitatively meaningful. Based on the semi-parametric estimation, the trade credit share rises by almost 2 percent between the first and the fifth transaction.

[Figure 4 here]

\subsection{Additional Results on Relationship Length}

In the following, we test additional predictions of the model on relationship length and its interactions with product complexity, contract enforcement, and markups.

\footnotetext{
${ }^{40}$ See appendix B.3 for an example of Bayesian learning that can micro-found the assumed learning dynamics and for further details on the simulation that generates panel B.
} 
Relationship Length and Contract Enforcement We begin by testing proposition 5, which predicts that the effect of learning on the trade credit choice is stronger for destinations with weaker contract enforcement. Table 7 presents results from regressions where we interact relationship length with two dummy variables that indicate if a country has a rule of law index above or below the median value in the sample. Results are consistent with the theoretical prediction: The effect of relationship length is at least twice as strong for destinations with poor rule of law than for destinations with a strong rule of law. Even more, in the balanced sample (column 4), relationship length only has a statistically significant effect on the trade credit share in destinations with a weak rule of law.

[Table 7 here]

Relationship Length and Product Complexity Proposition 6 predicts that the effect of learning on the use of trade credit should be stronger for more complex products. We test this prediction measuring product complexity by the degree of product differentiation as defined in Rauch (1999), assuming that differentiated products are more complex than homogeneous products. Figure 5 shows that the positive relationship between trade credit use and the length of relationships is indeed stronger for differentiated (left panel) than for non-differentiated products (right panel). Table 8 tests the different patterns in a regression framework, interacting the variable for relationship length with two categorical variables for differentiated and homogeneous products. Across all specifications, the effect of relationship length on trade credit is stronger for differentiated products.

[Figure 5 here]

[Table 8 here]

Relationship Length and Markups We have shown separately that trade credit use increases both in relationship length and in markups. Now, we examine whether both mechanisms co-occur, or if one of them dominates the other. To answer this question, we run a horse-race between the number of previous transactions and markups in explaining the share of trade credit.

Table 9 presents the results. Consider first columns 1 and 2, which show that both the number of previous interactions and the markup are positive and statistically significant, when 
entered into the estimation simultaneously. Magnitudes are also quite similar to the coefficients reported in tables 2 and 6.

[Table 9 here]

Proposition 3 predicts that the effect of learning on the trade credit choice declines in the number of transactions, while the effect of the markup increases. To test these predictions, we split the data into two samples: the first nine transactions in a relationship and all trade after 10 or more transactions. Results are presented in columns 3 and 4 of table 9 . For the first nine trades, the coefficient on relationship length is twice as large as the average effect in column 2, while the coefficient on markups turns insignificant (column 3). In contrast, when we move beyond the ninth transaction (column 4), the coefficient on relationship length is no longer significant - with a magnitude very precisely estimated at zero,-- while the positive coefficient on markups becomes statistically significant and is 50 percent larger than the average effect estimated in column 3. These results suggest that, in line with Proposition 3, the effect of learning is more important at the beginning of a relationship, while markups matter more in older relationships.

\subsection{Robustness Checks}

We performed several robustness checks using alternative specifications and considered a series of extensions. In this subsection, we discuss the most important robustness checks, relegating a more detailed discussion of these results to appendix E.

Firms with Low Export Shares. We begin with additional results that address endogeneity concerns about markups. While our main approach to address this issue is the instrumental variable approach presented earlier, we provide an additional robustness check where we restrict the sample to firms with low participation in export markets (export share below 50 percent). When restricting the sample this way, we focus the analysis on a sample where average markups mostly reflect firms' pricing decisions in the domestic market. Results in table E.1 are very similar to the baseline results in table 2.

Alternative Markup Estimates. We also study the extent to which our results are dependent on the particular specification used to estimate markups. Columns 1 to 3 in appendix table E.2 show that our baseline results are very similar when we use a Translog production function 
to derive the materials' output elasticity. In the same table, we show that using product-level price-cost margins that are directly reported in the survey as a measure of markups does not affect our results qualitatively. Coefficients are similar to the baseline case, but standard errors are slightly larger (columns 4-6 in table E.2).

Alternative Input Assignment. We examine if our results are dependent on the way inputs are assigned to outputs. In the baseline estimates, inputs are assigned to outputs using the share of variable costs used in each product. In the case of single-product firms, we do not need to assume this because all inputs are used in the production of a single final product. The same is true when we compute markups at the firm-level. Results in table E.4 show that our results also hold in these cases.

Alternative Measures for Relationships and Relationship Length. Finally, we check the sensitivity of our results on trade credit use and relationship length. We consider two robustness exercises. First, we define relationships at the destination level. Second, we replicate specification (26) using the cumulative FOB sales value as a proxy proxies relationship length. Table E.5 shows that our results are qualitatively unchanged from the baseline in both cases; even quantitatively, the coefficient sizes are not too different from the baseline. If anything, trade credit use seems to react more to the relationship length when using this alternative measure.

To summarize, our baseline results on markups are robust to restricting the sample to export transactions of firms that are mostly domestic, to using a Translog production function when estimating markups, and to restricting the sample to single-product firms or estimating markups at the firm level. Similarly, or results on trade credit use and relationship length are robust to using alternative definitions for relationships or relationship length.

\section{Concluding Remarks}

Trade credit is the most important form of short-term finance for U.S. firms. This paper studies transaction-level trade data from Chile, documenting two striking facts. First, trade credit use increases in markups. Second, trade credit use increases in relationship length. It proposes a model of trade credit choice with positive markups, a financial intermediation friction, and learning to rationalize these facts and the general dominance of trade credit for firm-to-firm 
transactions.

An important conceptional point of the model is that the choice that firms face is not between trade credit and bank finance, but rather whether the buyer or the seller borrows from a bank. If the seller borrows, she extends trade credit. If the buyer borrows, the seller receives cash in advance, which Mateut (2014) pointedly referred to as "reverse trade credit." The key result of the theory is that in the presence of positive markups and financial frictions, it is almost always better for the seller to borrow, as this minimizes the amount borrowed and hence financial intermediation costs.

As a consequence, the payment choice affects the aggregate level of borrowing, making the size of the financial sector endogenous. This prediction is qualitatively consistent with recent developments in aggregate U.S. data that show rising markups (as estimated by De Loecker and Eeckhout, 2017) and more use of trade credit over time (see figure A.2). As higher markups make trade credit more attractive, firms may rely more on that financing form and less on the formal financial sector. Future work should shed more light on the macro implications of our findings and how heterogeneity in the adoption of trade credit may affect the size and the development of the financial sector. The last point may be particularly relevant in the context of developing and emerging economies where financial frictions are larger and hence the potential savings from using trade credit more prominent. 


\section{References}

Ackerberg, Daniel A., Kevin Caves, and Garth Frazer, "Identification Properties of Recent Production Function Estimators," Econometrica, 2015, 83 (6), 2411-2451.

Adelino, Manuel, Miguel A Ferreira, Mariassunta Giannetti, and Pedro Pires, "Trade Credit and the Transmission of Unconventional Monetary Policy," Technical Report, National Bureau of Economic Research 2020.

Ahn, JaeBin, "Understanding trade finance: theory and evidence from transaction-level data," Technical Report, International Monetary Fund, Washington, DC 2014.

_ and Miguel Sarmiento, "Estimating the direct impact of bank liquidity shocks on the real economy: Evidence from letter-of-credit import transactions in Colombia," Review of International Economics, 2019, 27 (5), 1510-1536.

_ Mary Amiti, and David E Weinstein, "Trade finance and the great trade collapse," American Economic Review, 2011, 101 (3), 298-302.

Amberg, Niklas, Tor Jacobson, Erik Von Schedvin, and Robert Townsend, "Curbing shocks to corporate liquidity: The role of trade credit," Journal of Political Economy, Forthcoming.

_ , Tore Ellingsen, Tor Jacobson, and Erik von Schedvin, "Trade Credit and Capital Bias," Working Paper, Stockholm School of Economics 2020.

Amiti, Mary and David E. Weinstein, "Exports and Financial Shocks," The Quarterly Journal of Economics, 2011, 126 (4), 1841-1877.

Antràs, Pol and C Fritz Foley, "Poultry in Motion: A Study of International Trade Finance Practices," Journal of Political Economy, 2015, 123 (4), 853-901.

Araujo, Luis and Emanuel Ornelas, "Trust-Based Trade," CEP Discussion Papers 820, Centre for Economic Performance, LSE August 2007.

_ , Giordano Mion, and Emanuel Ornelas, "Institutions and export dynamics," Journal of International Economics, 2016, 98, 2-20.

Balkenborg, Dieter, M Boyer, Y Hiriart, and D Martimort, "Judgment-Proofness and Extended Liability in the Presence of Adverse Selection," in "Frontiers in the Economics of Environmental Regulation and Liability," Vol. 91, Ashgate Aldershot, 2006, pp. 265-290.

Barrot, Jean-Noël, "Trade credit and industry dynamics: Evidence from trucking firms," The Journal of Finance, 2016, 71 (5), 1975-2016.

Biais, Bruno and Christian Gollier, "Trade Credit and Credit Rationing," Review of Financial Studies, 1997, 10 (4), 903-37.

Brennan, Michael J, Vojislav Maksimovics, and Josef Zechner, "Vendor financing," The Journal of Finance, 1988, 43 (5), 1127-1141. 
Burkart, Mike and Tore Ellingsen, "In-Kind Finance: A Theory of Trade Credit," American Economic Review, June 2004, 94 (3), 569-590.

Cajal-Grossi, Julia, Rocco Macchiavello, and Guillermo Noguera, "International Buyers' Sourcing and Suppliers' Markups in Bangladeshi Garments," CEPR Discussion Paper 13482, C.E.P.R. Discussion Paper January 2019.

Chod, Jiri, Evgeny Lyandres, and S Alex Yang, "Trade credit and supplier competition," Journal of Financial Economics, 2019, 131 (2), 484-505.

Chor, Davin and Kalina Manova, "Off the cliff and back? Credit conditions and international trade during the global financial crisis," Journal of International Economics, 2012, 87 (1), $117-133$.

Daripa, Arup and Jeffrey Nilsen, "Ensuring sales: A theory of inter-firm credit," American Economic Journal: Microeconomics, 2011, 3 (1), 245-79.

De Loecker, Jan, "A Note on Detecting Learning by Exporting," American Economic Journal: Macroeconomics, 2013, 5 (3), 1-21.

- and Frederic Warzynski, "Markups and Firm-Level Export Status," American Economic Review, 2012, 102 (6), 2437-2471.

- and Pinelopi Koujianou Goldberg, "Firm Performance in a Global Market," Annual Review of Economics, 2014, 6 (1), 201-227.

_ , Pinelopi K. Goldberg, Amit K. Khandelwal, and Nina Pavcnik, "Prices, Markups and Trade Reform," Econometrica, 2016, 84 (2), 445-510.

Demir, Banu and Beata Javorcik, "Don't throw in the towel, throw in trade credit!," Journal of International Economics, 2018, 111, 177-189.

Demirguc-Kunt, Asli and Vojislav Maksimovic, "Firms as financial intermediaries - evidence from trade credit data," Policy Research Working Paper Series 2696, The World Bank October 2001.

Ellingsen, Tore, Tor Jacobson, and Erik L von Schedvin, "Trade credit: Contract-level evidence contradicts current theories," 2016. Stockholm School of Economics.

Emery, Gary W, "A pure financial explanation for trade credit," Journal of Financial and Quantitative Analysis, 1984, 19 (3), 271-285.

Ferris, J Stephen, "A transactions theory of trade credit use," The Quarterly Journal of Economics, 1981, 96 (2), 243-270.

Fischer, Christian, "Optimal payment contracts in trade relationships," 2020.

Fisman, Raymond and Inessa Love, "Trade credit, financial intermediary development, and industry growth," The Journal of finance, 2003, 58 (1), 353-374. 
Garcia-Marin, Alvaro and Nico Voigtländer, "Exporting and Plant-Level Efficiency Gains: It's in the Measure," Journal of Political Economy, 2019, 127 (4), 1777-1825.

Giannetti, Mariassunta, Mike Burkart, and Tore Ellingsen, "What You Sell Is What You Lend? Explaining Trade Credit Contracts," Review of Financial Studies, 2011, 24 (4), 1261-1298.

_, Nicolas Serrano-Velarde, and Emanuele Tarantino, "Cheap Trade Credit and Competition in Downstream Markets," CEPR Discussion Papers, C.E.P.R. Discussion Papers October 2018.

Hoefele, Andreas, Tim Schmidt-Eisenlohr, and Zhihong Yu, "Payment Choice in International Trade: Theory and Evidence from Cross-country Firm Level Data," Canadian Journal of Economics, 2016, 49 (1), 296-319.

Jacobson, Tor and Erik von Schedvin, "Trade credit and the propagation of corporate failure: an empirical analysis," Econometrica, 2015, 83 (4), 1315-1371.

Levinsohn, James and Amil Petrin, "Estimating Production Functions Using Inputs to Control for Unobservables," Review of Economic Studies, 2003, 70 (2), 317-341.

Loecker, Jan De and Jan Eeckhout, "The rise of market power and the macroeconomic implications," Technical Report, National Bureau of Economic Research 2017.

Love, Inessa, Lorenzo A Preve, and Virginia Sarria-Allende, "Trade credit and bank credit: Evidence from recent financial crises," Journal of Financial Economics, 2007, 83 (2), $453-469$.

Macchiavello, Rocco and Ameet Morjaria, "The Value of Relationships: Evidence from a Supply Shock to Kenyan Rose Exports," American Economic Review, September 2015, 105 (9), 2911-45.

Manova, Kalina, "Credit constraints, heterogeneous firms, and international trade," The Review of Economic Studies, 2013, 80 (2), 711-744.

Mateut, Simona, "Reverse trade credit or default risk? Explaining the use of prepayments by firms," Journal of Corporate Finance, 2014, 29, 303-326.

McMillan, John and Christopher Woodruff, "Interfirm Relationships and Informal Credit in Vietnam," The Quarterly Journal of Economics, 1999, 114 (4), 1285-1320.

Melitz, Marc J. and Giancarlo I. P. Ottaviano, "Market Size, Trade, and Productivity," Review of Economic Studies, 01 2008, 75 (1), 295-316.

Mian, Shehzad L and Clifford W Smith, "Accounts receivable management policy: theory and evidence," The Journal of Finance, 1992, 47 (1), 169-200.

Monarch, Ryan and Tim Schmidt-Eisenlohr, "Learning and the Value of Relationships in International Trade," CESifo Working Paper 5724, CESifo Group Munich 2016. 
_ and _, "Learning and the Value of Trade Relationships," January 2018. Federal Reserve Board of Governors, mimeo.

Murfin, Justin and Ken Njoroge, "The implicit costs of trade credit borrowing by large firms," The Review of Financial Studies, 2014, 28 (1), 112-145.

Myerson, Roger B, "Two-person bargaining problems with incomplete information," Econometrica: Journal of the Econometric Society, 1984, pp. 461-487.

Niepmann, Friederike and Tim Schmidt-Eisenlohr, "International trade, risk and the role of banks," Journal of International Economics, 2017, 10\%, 111-126.

_ and _ , "No guarantees, no trade: How banks affect export patterns," Journal of International Economics, 2017, 108, 338-350.

Nilsen, Jeffrey H, "Trade credit and the bank lending channel," Journal of Money, credit and Banking, 2002, pp. 226-253.

Olley, G. Steven and Ariel Pakes, "The Dynamics of Productivity in the Telecommunications Equipment Industry," Econometrica, 1996, 64 (6), 1263-1297.

Olsen, Morten, "How firms overcome weak international contract enforcement: repeated interaction, collective punishment and trade finance," 2016.

Paravisini, Daniel, Veronica Rappoport, Philipp Schnabl, and Daniel Wolfenzon, "Dissecting the effect of credit supply on trade: Evidence from matched credit-export data," The Review of Economic Studies, 2014, 82 (1), 333-359.

Petersen, Mitchell A and Raghuram G Rajan, "Trade Credit: Theories and Evidence," Review of Financial Studies, 1997, 10 (3), 661-91.

Peura, Heikki, S. Alex Yang, and Guoming Laic, "Trade Credit in Competition: A Horizontal Benefit," Manufacturing 85 Service Operations Management, 2017, 19 (2), 263289.

Rauch, James E., "Networks versus markets in international trade," Journal of International Economics, 1999, 48 (1), 7-35.

Schmidt-Eisenlohr, Tim, "Towards a Theory of Trade Finance," Working Paper 3414, CESifo 2011.

_ , "Towards a theory of trade finance," Journal of International Economics, 2013, 91 (1), 96 -112 .

Schwartz, Robert A, "An economic model of trade credit," Journal of financial and quantitative analysis, 1974, 9 (4), 643-657.

Schwartz, Robert Alan and David K Whitcomb, "The trade credit decision," in J. Bicksler, ed., Handbook of Financial Ecnomics, 1979.

Smith, Janet Kiholm, "Trade credit and informational asymmetry," The journal of finance, 1987, 42 (4), 863-872. 


\section{Tables}

Table 1. Summary Statistics

\begin{tabular}{lcccccc}
\hline \hline & Mean & Std. Dev. & P25 & P50 & P75 & Obs. \\
\cline { 2 - 7 } & $(1)$ & $(2)$ & $(3)$ & $(4)$ & $(5)$ & $(6)$ \\
\hline Transaction Characteristics (full sample) & & & & & & \\
Trade Credit Dummy & 0.8854 & 0.3140 & 1 & 1 & 1 & 608,588 \\
Cash in advance Dummy & 0.0521 & 0.2258 & 0 & 0 & 0 & 608,588 \\
Letters of Credit Dummy & 0.0555 & 0.2206 & 0 & 0 & 0 & 608,588 \\
Export Value (US\$) & 137,434 & $1,192,711$ & $3,632.8$ & $14,310.4$ & $49,095.5$ & 608,588 \\
& & & & & & \\
Transaction Characteristics (excluding old relationships) & 0.8623 & 0.3140 & 1 & 1 & 1 & 212,940 \\
Trade Credit Dummy & 0.0723 & 0.2318 & 0 & 0 & 0 & 212,940 \\
Cash in advance Dummy & 0.0581 & 0.2580 & 0 & 0 & 0 & 212,940 \\
Letters of Credit Dummy & 103,065 & 889,079 & 2,520 & $10,400.0$ & $38,288.7$ & 212,940 \\
Export Value (US\$) & & & & & & \\
& & & & & & \\
Firm-product Characteristics & 273.2 & 522.3 & 51 & 119 & 283 & 3,546 \\
$\quad$ Employment (at the firm level) & 0.153 & 0.373 & -0.125 & 0.105 & 0.383 & 26,584 \\
Markups (in logs) & 22.9 & 59.3 & 1 & 5 & 18 & 26,584 \\
\# Transactions by firm-product-year & 3.5 & 5.3 & 1 & 1 & 4 & 26,584 \\
\# Destinations by firm-product-year & & & & & & \\
Country Characteristics & & & & & & \\
Rule of Law Index & 0.36189 & 1.00966 & -0.56894 & 0.38070 & 1.26830 & 362 \\
Foreign borrowing rate & 0.05466 & 0.04521 & 0.02717 & 0.04505 & 0.06924 & 362 \\
Chilean deposit rate & 0.00929 & 0.00579 & 0.00879 & 0.00883 & 0.01202 & 362 \\
\hline \hline
\end{tabular}

Notes: The table lists the summary statistics for the variables used in the paper's baseline analysis sample. It comprises transaction-level data for the universe of Chilean manufacturing exporters that can be matched to the Chilean Annual Manufacturing Survey (ENIA), over the period 2003-2007. Relationships are defined at the level of firm-product-destinations. We define as 'old' to all relationships that started before 2003. 
Table 2. Trade Credit Share and Firm-Product Markup: Baseline Regressions

\begin{tabular}{|c|c|c|c|c|c|c|}
\hline Dependent Variable: & $\begin{array}{c}\text { OLS } \\
(1) \\
\text { TC Share }\end{array}$ & $\begin{array}{c}\text { Initial/OLS } \\
(2) \\
\text { TC Share }\end{array}$ & $\begin{array}{c}\text { Average/OLS } \\
(3) \\
\text { TC Share }\end{array}$ & $\begin{array}{c}\text { Reduced Form } \\
(4) \\
\text { TC Share }\end{array}$ & $\begin{array}{c}\text { First Stage } \\
(5) \\
\ln (\text { markup })\end{array}$ & $\begin{array}{c}\text { Second Stage } \\
(6) \\
\text { TC Share }\end{array}$ \\
\hline $\ln ($ markup) & $\begin{array}{c}.0204^{* * *} \\
(.0047)\end{array}$ & $\begin{array}{c}.0721^{* * *} \\
(.0206)\end{array}$ & $\begin{array}{c}.0355^{* * *} \\
(.0133)\end{array}$ & - & - & $\begin{array}{c}.1050^{* * *} \\
(.0291)\end{array}$ \\
\hline $\ln (\mathrm{TFPQ})$ & - & - & - & $\begin{array}{c}.0054^{* * *} \\
(.0015)\end{array}$ & $\begin{array}{c}.0519^{* * *} \\
(.0038)\end{array}$ & - \\
\hline First Stage F-Statistic & - & - & - & - & 232.2 & - \\
\hline HS8 FE & $\checkmark$ & $\checkmark$ & $\checkmark$ & $\checkmark$ & $\checkmark$ & $\checkmark$ \\
\hline Firm FE & $\checkmark$ & $\checkmark$ & $\checkmark$ & $\checkmark$ & $\checkmark$ & $\checkmark$ \\
\hline Country-Year FE & $\checkmark$ & $\checkmark$ & $\checkmark$ & $\checkmark$ & $\checkmark$ & $\checkmark$ \\
\hline Observations & 93,556 & 93,556 & 93,556 & 90,727 & 90,727 & 90,727 \\
\hline $\mathrm{R}^{2}$ & .368 & .368 & .368 & .371 & .692 & .368 \\
\hline
\end{tabular}

Notes: All regressions are run at the firm-product-destination level (with products defined at the HS8level). Trade credit shares are computed as the ratio of the FOB value of trade credit transactions to the FOB value of all export transactions over a year. Markups are computed at the firm-product level. Columns 1-3 report OLS estimates. Column 4 report the reduced form for the trade credit share against TFPQ. The first stage results of the 2SLS regressions are reported in column 5, together with the (clusterrobust) Kleibergen-Paap rKWald F-statistic. The corresponding Stock-Yogo value for 10\% maximal IV bias is 16.4. Second stage results are reported in column 6. Standard errors (in parentheses) are clustered at the firm-product level. Key: *** significant at $1 \% ; * * 5 \% ; * 10 \%$.

Table 3. Trade Credit Share and Firm-Product Markup: Heterogeneity

\begin{tabular}{l|cccc|cccc}
\hline \hline Specification & $\begin{array}{c}\text { OLS } \\
(1)\end{array}$ & $\begin{array}{c}\text { OLS } \\
(2)\end{array}$ & $\begin{array}{c}\text { OLS } \\
(3)\end{array}$ & $\begin{array}{c}\text { OLS } \\
(4)\end{array}$ & $\begin{array}{c}\text { 2SLS } \\
(5)\end{array}$ & $\begin{array}{c}\text { 2SLS } \\
(6)\end{array}$ & $\begin{array}{c}\text { 2SLS } \\
(7)\end{array}$ & $\begin{array}{c}\text { 2SLS } \\
(8)\end{array}$ \\
\hline $\ln ($ markup) & -.0215 & -.0298 & - & - & $.539^{* *}$ & $.459^{* *}$ & - & - \\
& $(.0311)$ & $(.0318)$ & & & $(.222)$ & $(.226)$ & & \\
$\ln ($ markup $) \times \mathrm{r}_{d}$ & -.533 & -.485 & - & - & -2.130 & -1.551 & - & - \\
& $(2.510)$ & $(2.512)$ & & & $(17.34)$ & $(17.64)$ & & \\
$\ln ($ markup $) \times \mathrm{r}_{b}^{*}$ & $.293^{* *}$ & $.328^{* * *}$ & $.308^{* *}$ & $.343^{* *}$ & $.953^{*}$ & $1.232^{* *}$ & $1.136^{* *}$ & $1.363^{* *}$ \\
& $.121)$ & $(.126)$ & $(.135)$ & $(.141)$ & $(.545)$ & $(.562)$ & $(.569)$ & $(.587)$ \\
$\ln ($ markup$) \times$ Rule of Law & - & .0212 & - & .0212 & - & $.239^{*}$ & - & .209 \\
& & $(.0151)$ & & $(.0164)$ & & $(.137)$ & & $(.147)$ \\
\hline First Stage F-Statistic & - & - & - & - & 21.1 & 16.5 & 51.7 & 26.9 \\
\hline Firm-Year FE & $\checkmark$ & $\checkmark$ & - & - & $\checkmark$ & $\checkmark$ & - & - \\
HS8 FE & $\checkmark$ & $\checkmark$ & - & - & $\checkmark$ & $\checkmark$ & - & - \\
Country-Year FE & $\checkmark$ & $\checkmark$ & $\checkmark$ & $\checkmark$ & $\checkmark$ & $\checkmark$ & $\checkmark$ & $\checkmark$ \\
Firm-HS8-Year FE & - & - & $\checkmark$ & $\checkmark$ & - & - & $\checkmark$ & $\checkmark$ \\
\hline Observations & 93,556 & 93,556 & 93,556 & 93,556 & 90,727 & 90,727 & 90,727 & 90,727 \\
$\mathrm{R}^{2}$ & .420 & .420 & .437 & .437 & .409 & .402 & .435 & .430 \\
\hline \hline
\end{tabular}

Notes: The table reports the coefficient estimates from equation (25). All regressions are run at the firm-product-destination level (with products defined at the HS8-level). Trade credit share corresponds to the ratio of the FOB value of trade credit transactions to the FOB value of all export transactions over a year. Markups are computed at the firm-product level (products are defined at the 5-digit CPC level). All regressions control for the logarithm of firm employment. Standard errors (in parentheses) are clustered at the firm-destination level. Key: $* * *$ significant at $1 \% ; * * 5 \% ; * 10 \%$. 
Table 4. Relative use of Financing Terms (\%)

\begin{tabular}{l|cccc}
\hline \hline & $\begin{array}{c}\text { Trade Credit } \\
\text { Share }\end{array}$ & $\begin{array}{c}\text { Cash in } \\
\text { Advance Share }\end{array}$ & $\begin{array}{c}\text { Letter of } \\
\text { Credit Share }\end{array}$ & $\begin{array}{c}\text { Other } \\
\text { Payment Forms }\end{array}$ \\
\hline All customers & 89 & 5 & 5 & 1 \\
\hline New relationship & 79 & 12 & 7 & 2 \\
New destination (any product) & 75 & 14 & 9 & 2 \\
New exporter (any product or destination) & 66 & 17 & 9 & 8 \\
\hline
\end{tabular}

Notes: The table shows the percentage of transactions financed through trade credit terms (column 1), cash in advance terms (column 2), letter of credit terms (column 3), and other forms of payment (column 4). 'New relationship', 'New destination' and 'New exporter' consider the first transaction within a relationship, export destination, and exporter, respectively.

Table 5. Transition Probability Between Payments Forms (\%)

\begin{tabular}{l|cccc}
\hline \hline & $\begin{array}{c}\text { Trade } \\
\text { Credit }\end{array}$ & $\begin{array}{c}\text { Cash in } \\
\text { Advance }\end{array}$ & $\begin{array}{c}\text { Letter of } \\
\text { Credit }\end{array}$ & $\begin{array}{c}\text { Other } \\
\text { Payment Forms }\end{array}$ \\
\hline Trade Credit & 94 & 3 & 2 & 1 \\
Cash in advance & 29 & 66 & 3 & 2 \\
Letters of Credit & 29 & 4 & 64 & 3 \\
Other Payment Forms & 94 & 8 & 12 & 30 \\
\hline \hline
\end{tabular}

Notes: The table shows transition probabilities in payment forms within relationships. Each cell shows the percentage of transactions financed through each row payment form in period t that are financed through the column payment form in period $\mathrm{t}+1$.

Table 6. Relationship Length and Trade Credit Share

\begin{tabular}{lcccc}
\hline \hline & $(1)$ & $(2)$ & $(3)$ & $(4)$ \\
\hline $\ln ($ Relationship Length) & $.0127^{* * *}$ & $.0056^{* * *}$ & $.0064^{* * *}$ & $.0067^{* * *}$ \\
& $(.00130)$ & $(.00138)$ & $(.00135)$ & $(.00218)$ \\
\hline Sample & All & All & All & Balanced \\
\hline Firm-HS8-Country FE & Yes & Yes & Yes & Yes \\
Country-Year FE & - & Yes & Yes & Yes \\
Firm-HS8-Year FE & - & - & Yes & Yes \\
\hline Observations & 212,940 & 212,940 & 212,940 & 47,264 \\
$\mathrm{R}^{2}$ & .675 & .682 & .728 & .723 \\
\hline \hline
\end{tabular}

Notes: The table regresses the trade credit share on the logarithm of the number of previous interactions. All regressions are run at the transaction level (with products defined at the HS8-level). Trade credit share corresponds to the ratio of the FOB value of trade credit transactions to the FOB value of all export transactions over a year. Regressions in columns 1 and 2 control for the logarithm of firm employment. Standard errors (in parentheses) are clustered at the firmproduct-destination level. Key: ${ }^{* * *}$ significant at $1 \% ;{ }^{* *} 5 \% ;{ }^{*} 10 \%$. 
Table 7. Relationship Length and Destination's Contract Enforcement

\begin{tabular}{lcccc}
\hline \hline & $(1)$ & $(2)$ & $(4)$ & $(5)$ \\
\hline $\ln \left(\right.$ Relationship Length) ${ }^{*}$ Low ROL & $.0189^{* * *}$ & $.0074^{* * *}$ & $.0086^{* * *}$ & $.0098^{* * *}$ \\
& $(.0021)$ & $(.0020)$ & $(.0018)$ & $(.0035)$ \\
$\ln$ (Relationship Length) ${ }^{*}$ High ROL & $.0059^{* * *}$ & $.0039^{* *}$ & $.0044^{* *}$ & .0038 \\
& $(.0014)$ & $(.0019)$ & $(.0019)$ & $(.0027)$ \\
\hline Sample & All & All & All & Balanced \\
\hline Firm-HS8-Country FE & Yes & Yes & Yes & Yes \\
Country-Year FE & - & Yes & Yes & Yes \\
Firm-HS8-Year FE & - & - & Yes & Yes \\
\hline Observations & 212,940 & 212,940 & 212,940 & 47,264 \\
$\mathrm{R}^{2}$ & .680 & .685 & .732 & .723 \\
\hline \hline
\end{tabular}

Notes: The table regresses the trade credit share on the logarithm of the number of previous interactions, interacted with two categorical variables that indicate if the destination country has a Rule of Law index above or below the median index across all countries. All regressions are run at the transaction level (with products defined at the HS8-level). Trade credit share corresponds to the ratio of the FOB value of trade credit transactions to the FOB value of all export transactions over a year. Regressions 1-2 control for the logarithm of firm employment. Standard errors (in parentheses) are clustered at the firm-product-destination level. Key: *** significant at $1 \% ; * * 5 \% ; 10 \%$. ROL $=$ Rule of Law Index.

Table 8. Relationship Length and Product Differentiation

\begin{tabular}{lcccc}
\hline \hline & $(1)$ & $(2)$ & $(3)$ & $(4)$ \\
\hline $\ln$ (Relationship Length) ${ }^{*}$ Differentiated & $.0171^{* * *}$ & $.0086^{* * *}$ & $.0076^{* * *}$ & $.0125^{* * *}$ \\
& $(.0026)$ & $(.0025)$ & $(.0029)$ & $(.0041)$ \\
$\ln$ (Relationship Length) ${ }^{*}$ Homogeneous & $.0099^{* * *}$ & $.0037^{* *}$ & $.0066^{* * *}$ & .0032 \\
& $(.0014)$ & $(.0015)$ & $(.0014)$ & $(.0025)$ \\
\hline Sample & All & All & All & Balanced \\
\hline Firm-HS8-Country FE & Yes & Yes & Yes & Yes \\
Country-Year FE & - & Yes & Yes & Yes \\
Firm-HS8-Year FE & - & - & Yes & Yes \\
\hline Observations & 212,940 & 212,940 & 212,940 & 47,264 \\
$\mathrm{R}^{2}$ & .675 & .682 & .728 & .723 \\
\hline \hline
\end{tabular}

Notes: The table regresses the trade credit share on the logarithm of the number of previous interactions, interacted with two categorical variables that indicate if the product is homogeneous or differentiated according to the liberal product classification of Rauch (1999). All regressions are run at the transaction level (with products defined at the HS8-level). Trade credit share corresponds to the ratio of the FOB value of trade credit transactions to the FOB value of all export transactions over a year. Regressions 1-2 control for the logarithm of firm employment. Standard errors (in parentheses) are clustered at the firm-product-destination level. Key: *** significant at $1 \% ; * * 5 \% ; 10 \%$. 
Table 9. Trade Credit, Markup and Relationship Length: 2SLS Results

\begin{tabular}{lcccc}
\hline \hline & $(1)$ & $(2)$ & $(3)$ & $(4)$ \\
\hline $\ln$ (Relationship Length) & $.0129^{* * *}$ & $.0063^{* * *}$ & $.0129^{* * *}$ & .0004 \\
& $(.0014)$ & $(.0015)$ & $(.0016)$ & $(.0034)$ \\
$\ln$ (Markup) & $.0716^{* *}$ & $.0759^{* *}$ & .0451 & $.1010^{* *}$ \\
& $(.0312)$ & $(.0326)$ & $(.0540)$ & $(.0488)$ \\
First-Stage F-Statistic & 72.0 & 76.4 & 121.5 & 22.6 \\
\hline Relationships & All & All & $<10$ trades & $\geq 10$ trades \\
\hline Firm-HS8-Country FE & Yes & Yes & Yes & Yes \\
Country-Year FE & - & Yes & Yes & Yes \\
\hline Observations & 203,885 & 203,885 & 111,217 & 92,668 \\
$\mathrm{R}^{2}$ & .678 & .685 & .720 & .698 \\
\hline \hline
\end{tabular}

Notes: The table regresses the trade credit share on the logarithm of the number of previous interactions and firm-product markups. All regressions are run at the transaction-level (with products defined at the HS8-level) and use firm-product TFPQ to instrument for markups. The table only shows second-stage results, together with the corresponding (cluster-robust) Kleibergen-Paap rKWald F-statistic. The StockYogo value for $10 \%$ maximal IV bias is 16.4. Trade credit share corresponds to the ratio of the FOB value of trade credit transactions to the FOB value of all export transactions over a year. Markups are computed at the firm-product level (products are defined at the 5-digit CPC level). Regression 1 controls for the logarithm of firm employment. Standard errors (in parentheses) are clustered at the firm-productdestination level. Key: *** significant at $1 \%$; ** $5 \%$; $10 \%$. 


\section{Figures}

Figure 1. Trade Credit Increases with Markups and Relationship Length
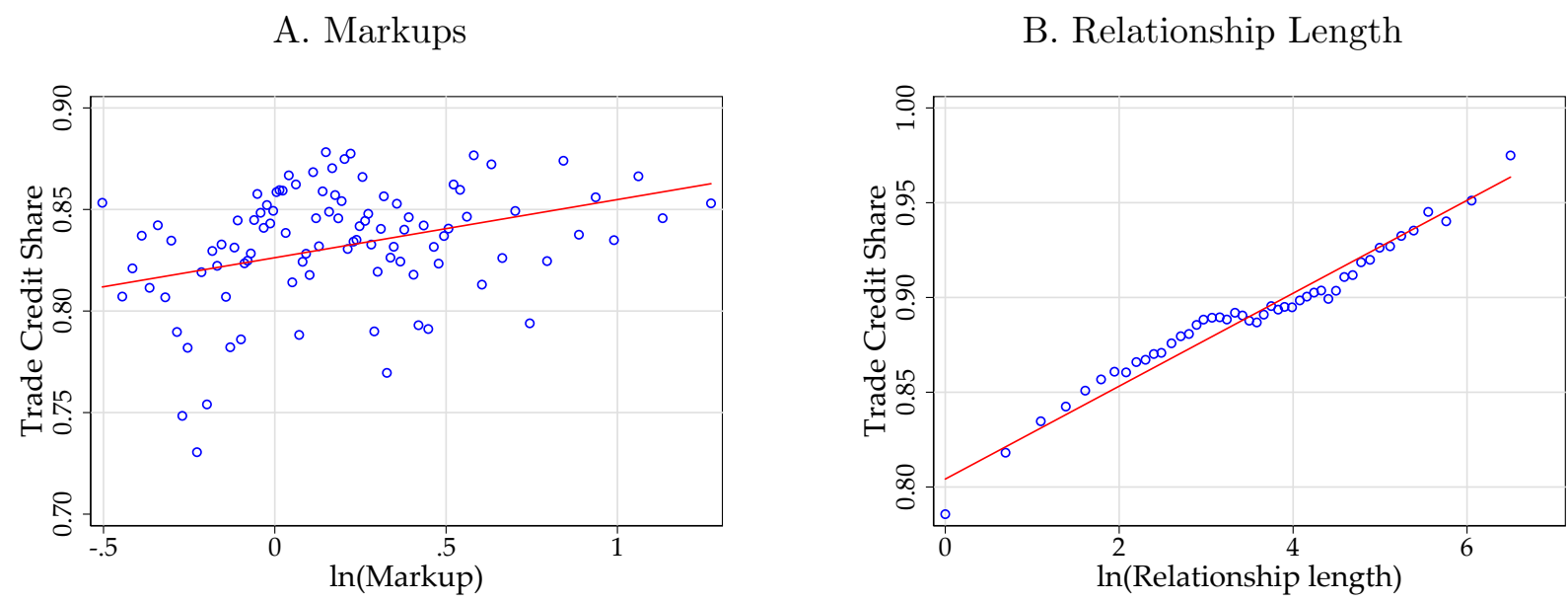

Notes: The figures show binscatter diagrams where the average trade credit share in each bin is plotted against markups (panel A), and relationship length (panel B). Markups are computed at the firmproduct level as in De Loecker et al. (2016). Relationship length is measured in terms of the number of transactions in each destination and product. Markups and relationship length are expressed in terms of logarithms. Both figures control for destination-year fixed effects. 
Figure 2. Trade Credit Share, Markups and Interest Rates

High Interest Rate Destinations

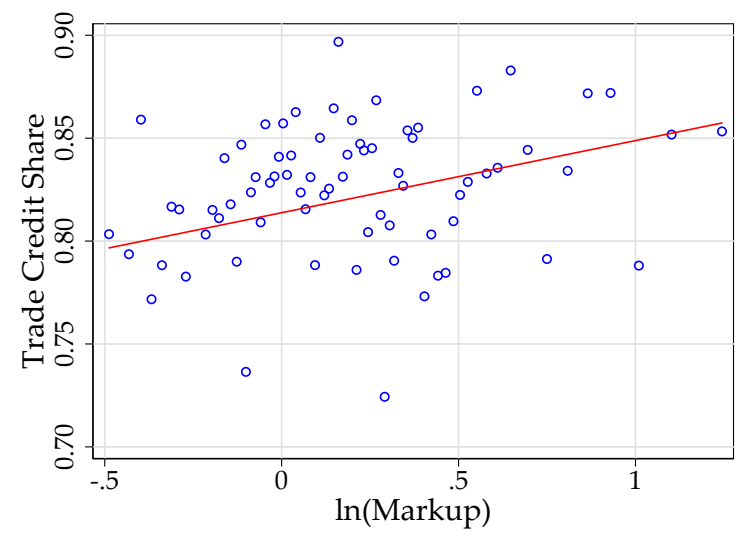

Low Interest Rate Destinations

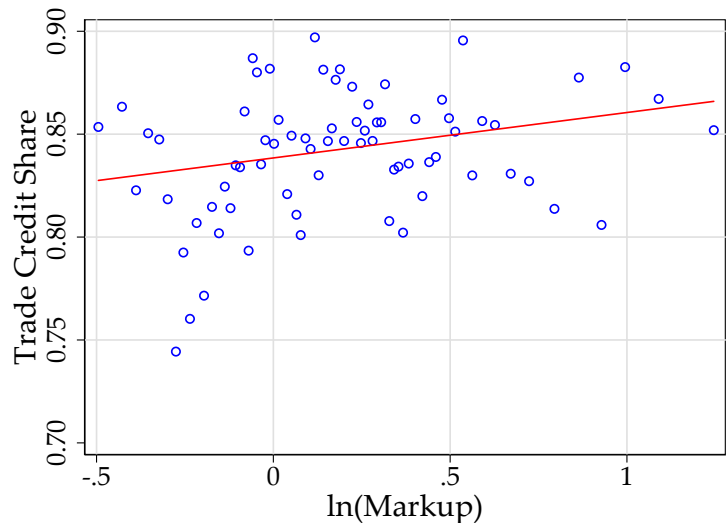

Notes: The figures show binscatter plots of the trade credit share against markups (in logs). Panel A shows export destinations with borrowing rates above the median rate across destinations. Panel B shows export destinations with borrowing rates below the median rate across destinations. The trade credit share is computed at the firm-product-destination level, and markups are computed at the firm-product level, following the methodology by De Loecker et al. (2016). Both figures control for destination-year fixed effects.

Figure 3. Trade Credit Share and the Length of the Relationship

A. Trade Credit

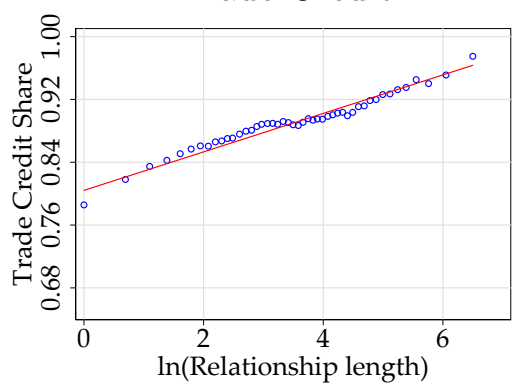

B. Cash in Advance

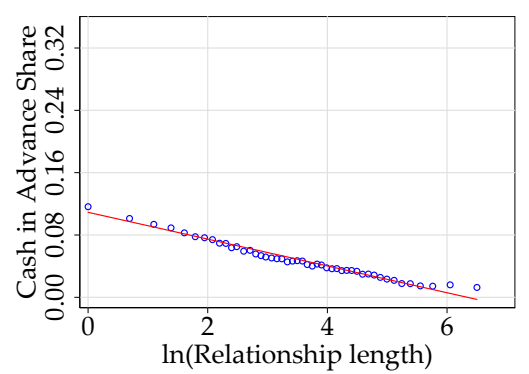

C. Letter of Credit

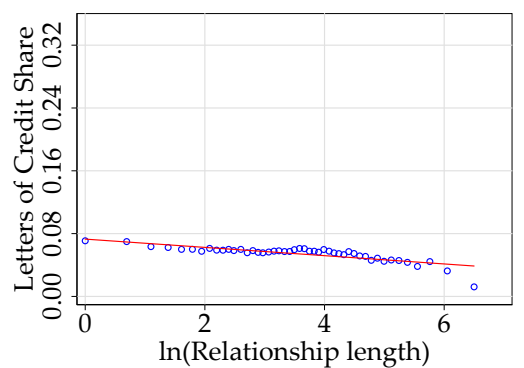

Notes: The figure plots the frequency of use of the three main financial contracts in the Chilean data, and the length of the buyer-seller relationship. Relationship length is defined as the cumulative number of transactions occurring from the beginning of the relation. Relationships are defined as customer locations as in Antràs and Foley (2015). All figures control for destination-year fixed effects. 
Figure 4. Trade Credit and Relationship Length: Semi-Parametric Estimation

\section{A. Semi-parametric Estimation}

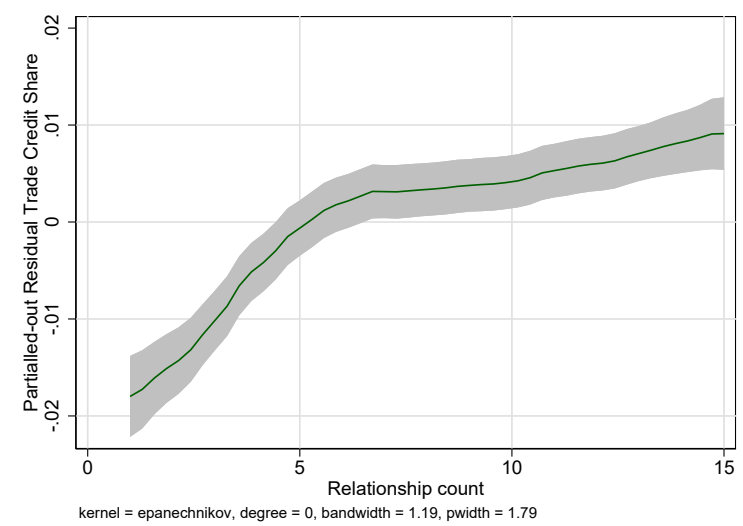

B. Learning Model

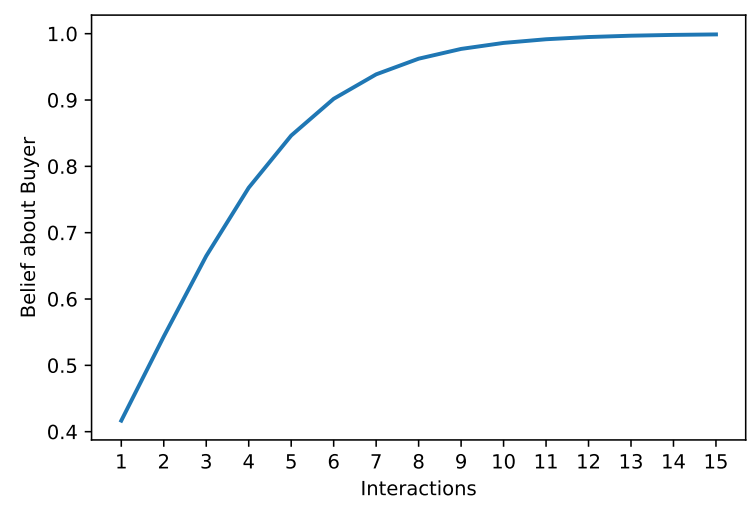

Notes: Panel A plots the trade-credit share against the number of transactions within a relationship. Panel B illustrates the typical Bayesian learning process (with parameters $\hat{\eta}=0.3$ and $\lambda=0.6$, see appendix B.3 for details).

Figure 5. Relationships and Trade Credit Share
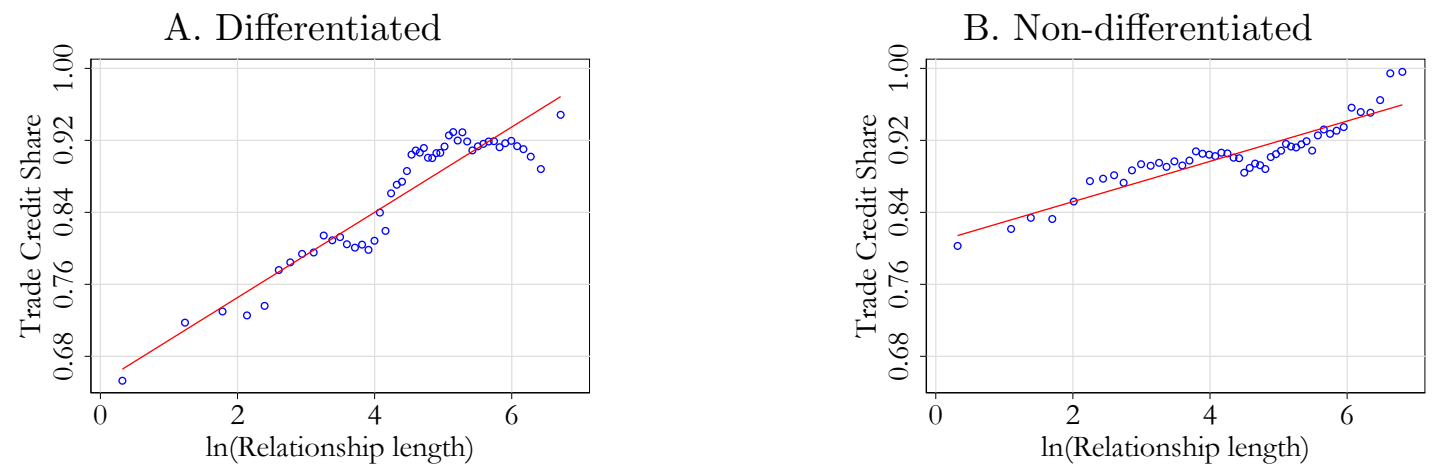

Notes: The figure plots the frequency of use of trade credit account contracts and the length of the buyer-seller relationship. Differentiated products are defined (at the 6-digit HS level) according to the liberal product classification of Rauch (1999). Relationship length is defined as the cumulative number of transactions occurring from the beginning of the relation. Relationships are defined as customer locations as in Antràs and Foley (2015). 


\section{A Trade Credit and Markups in the United States Over Time}

Figure A.1. Trade Credit and Markups in the U.S.

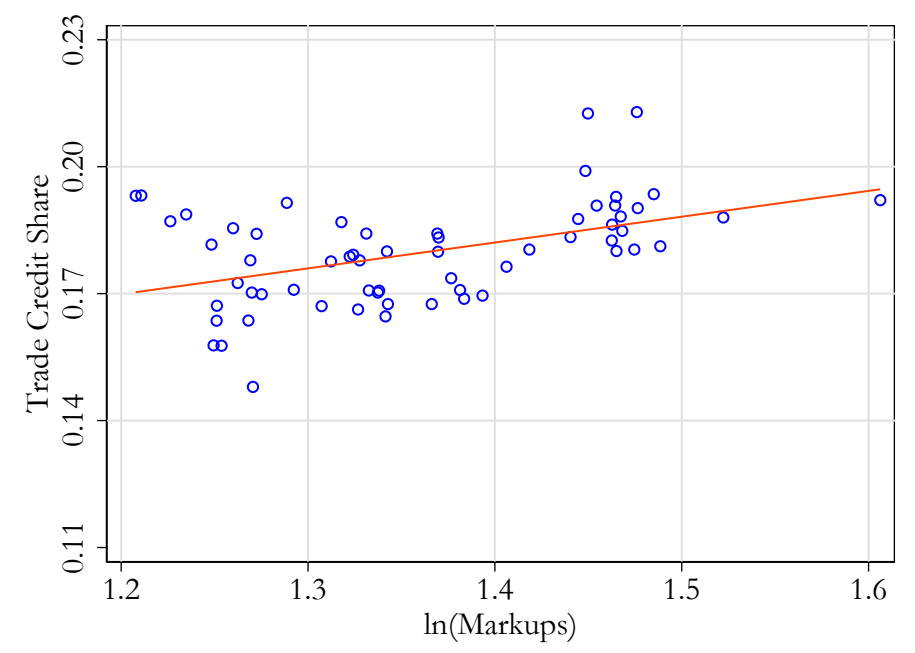

Notes: This figure plots the total trade credit receivables of the non-financial corporate and noncorporate sectors against the markups as estimated by De Loecker and Eeckhout (2017).

Figure A.2. Trade Credit and Markups in the U.S.

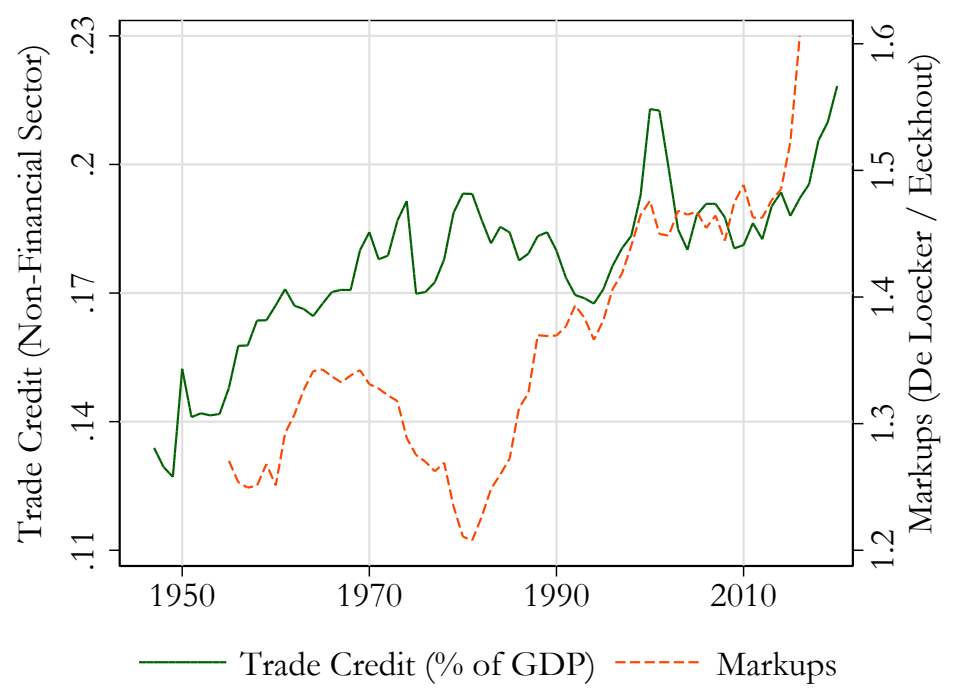

Notes: This figure shows the time series of the total trade credit receivables of the non-financial corporate and non-corporate sectors over GDP on the left Y-axis. On the right Y-axis, it shows the markups as estimated by De Loecker and Eeckhout (2017). 


\section{B Theory Appendix}

\section{B.1 Solving the model with CES and monopolistic competition}

Assume that firms operate under monopolistic competition and that final consumers have CES preferences with demand:

$$
q=p^{-\sigma} A
$$

where $\sigma$ is the elasticity of substitution between varieties and $A$ reflects the aggregate level of demand. Expected profits of the seller are given by:

$$
\begin{aligned}
\mathrm{E}\left[\Pi_{S}^{O A}\right] & =\left(\tilde{\lambda}^{*} p-\left(1+r_{b}\right) c\right) q \\
\mathrm{E}\left[\Pi_{S}^{C I A}\right] & =\left(\tilde{\lambda} \frac{1+r_{d}}{1+r_{b}^{*}} p-\left(1+r_{d}\right) c\right) q
\end{aligned}
$$

Solving the model delivers the following optimal prices charged to final consumers:

$$
\begin{aligned}
p^{O A} & =\frac{1+r_{b}}{\tilde{\lambda}^{*}} \frac{\sigma}{\sigma-1} c \\
p^{C I A} & =\frac{1+r_{b}^{*}}{\tilde{\lambda}} \frac{\sigma}{\sigma-1} c
\end{aligned}
$$

We can plug in the CES quantity $q$ and price $p^{O A}$ into the expected profit for trade credit to get:

$$
\mathrm{E}\left[\Pi_{S}^{O A}\right]=\left(\tilde{\lambda}^{*}\right)^{\sigma}\left(1+r_{b}\right)^{1-\sigma} \frac{c^{1-\sigma}}{\sigma-1}\left(\frac{\sigma}{\sigma-1}\right)^{-\sigma} A
$$

For Cash in Advance, we get:

$$
\mathrm{E}\left[\Pi_{S}^{C I A}\right]=(\tilde{\lambda})^{\sigma}\left(1+r_{d}\right)\left(1+r_{b}^{*}\right)^{-\sigma} \frac{c^{1-\sigma}}{\sigma-1}\left(\frac{\sigma}{\sigma-1}\right)^{-\sigma} A
$$

Combining the two conditions, we get that trade credit is preferred over Cash in Advance if:

$$
\left(\tilde{\lambda}^{*}\right)^{\sigma}\left(1+r_{b}\right)^{1-\sigma}-\left(1+r_{d}\right)\left(1+r_{b}^{*}\right)^{-\sigma}(\tilde{\lambda})^{\sigma}>0
$$


Or, rewriting for interpretation:

$$
\left(\frac{\tilde{\lambda}^{*}}{\tilde{\lambda}}\right)^{\sigma}\left(\frac{1+r_{b}}{1+r_{b}^{*}}\right)^{1-\sigma}>\frac{1+r_{d}}{1+r_{b}^{*}}
$$

Within a country, the equation simplifies to:

$$
1>\frac{1+r_{d}}{1+r_{b}}
$$

which always holds when $r_{b}>r_{d}$. We can also take the derivative of equation (8) with respect to $\sigma$. This delivers:

$$
\left(\tilde{\lambda}^{*}\right)^{\sigma}\left(1+r_{b}\right)^{1-\sigma}\left(\ln \tilde{\lambda}^{*}+\ln \left(\frac{1}{1+r_{b}}\right)\right)-\left(1+r_{d}\right)\left(1+r_{b}^{*}\right)^{-\sigma}(\tilde{\lambda})^{\sigma}\left(\ln \tilde{\lambda}+\ln \left(\frac{1}{1+r_{b}^{*}}\right)\right)
$$

This derivative is negative when equation (8) is positive. That is, when markups decline (larger $\sigma)$, the preference for trade credit declines as well.

\section{B.2 Derivations for pooling and separating cases}

This section derives conditions under which it is optimal for unreliable firms to imitate reliable firms and for sellers to offer terms that both types of buyers accept. The following exposition builds on and extends the analysis in Schmidt-Eisenlohr (2013). In particular, we need to look at four cases:

1. The seller asks for a payment that is only accepted by unreliable buyers under trade credit.

2. The reliable seller chooses cash in advance, but the unreliable seller chooses trade credit.

3. The seller asks for a payment that is only accepted by unreliable buyers under cash in advance.

4. The reliable seller chooses trade credit, but the unreliable seller chooses cash in advance. 
Trade Credit - pooling case This is the baseline case discussed in the main text. The seller maximizes:

$$
\begin{aligned}
\mathrm{E}\left[\Pi_{S}^{T C, P}\right] & =\tilde{\lambda}^{*} P^{T C, P}-\left(1+r_{b}\right) C, \\
\text { s.t. } \mathrm{E}\left[\Pi_{R B}^{T C, P}\right] & =R-P^{T C, P} \geq 0,
\end{aligned}
$$

and chooses $P^{T C, P}=R$. This implies the following expected profits for both reliable and unreliable sellers under pooling:

$$
\mathrm{E}\left[\Pi_{S}^{T C, P}\right]=\tilde{\lambda}^{*} R-\left(1+r_{b}\right) C
$$

Trade Credit, Separating Case 1 As discussed in Case 1 above, the seller could ask for a payment that is only acceptable for unreliable buyers. Then, the payment exceeds revenues, $P^{T C, S}>R$. Unreliable buyers still accept this contract, as they know that they can deviate with probability $\lambda^{*}$. Expected profits of an unreliable buyer under separation are:

$$
\mathrm{E}\left[\Pi_{U B}^{T C, S}\right]=R-\lambda^{*} P^{T C, S}
$$

In this case, the seller picks $P^{T C, S}=\frac{R}{\lambda^{*}}$. Importantly, reliable buyers now reject the contract, so that the exporter only gets the initial contract accepted with probability $1-\eta^{*}$, the share of unreliable firms. Expected profits of a seller under a separating contract are hence:

$$
\mathrm{E}\left[\Pi_{S}^{T C, S}\right]=\left(1-\eta^{*}\right)\left(R-\left(1+r_{b}\right) C\right)
$$

Combining equations (11) and (12), a seller picks the pooling case as long as:

$$
\mathrm{E}\left[\Pi_{S}^{T C, P}\right]>\mathrm{E}\left[\Pi_{S}^{T C, S}\right] \Leftrightarrow\left(\eta^{*}-\left(1-\eta^{*}\right)\left(1-\lambda^{*}\right)\right) R>\eta^{*}\left(1+r_{b}\right) C
$$

As long as this condition holds, we can exclude Case 1. The condition is relatively weak. For example, suppose $\eta^{*}=0.8, \lambda^{*}=0.8$, and $1+r_{b}=1.025$ (annual rate of 10 percent if trade credit is for 3 months). Then the markup $\mu=R / C$ has to be larger than 1.08. The markup can be smaller if the share of reliable firms $\eta^{*}$ is larger, if contract enforcement $\lambda^{*}$ is stronger, or if the borrowing rate $1+r_{b}$ is lower. 
Trade Credit, Separating Case 2 Can it be optimal for the unreliable seller to choose trade credit when the reliable seller chooses cash in advance? No, because under trade credit both types of sellers have the same expected profits, and unreliable sellers have larger expected profits under cash in advance than under trade credit.

Cash in Advance - pooling case Under cash in advance, the reliable seller maximizes:

$$
\begin{aligned}
\mathrm{E}\left[\Pi_{R S}^{C I A, P}\right] & =\left(1+r_{d}\right)\left(P^{C I A, P}-C\right), \\
\text { s.t. } \mathrm{E}\left[\Pi_{B}^{C I A, P}\right] & =\tilde{\lambda} R-\left(1+r_{b}^{*}\right) P^{C I A, P} \geq 0 .
\end{aligned}
$$

Solving for the optimal $P^{C I A, P}$ delivers $P^{C I A, P}=\frac{\tilde{\lambda}}{1+r_{b}^{*}} R$. With expected profits of:

$$
\mathrm{E}\left[\Pi_{R S}^{C I A, P}\right]=\left(1+r_{d}\right)\left(\frac{\tilde{\lambda}}{1+r_{b}^{*}} R-C\right) .
$$

An unreliable seller has expected profits of:

$$
\mathrm{E}\left[\Pi_{U S}^{C I A, P}\right]=\left(1+r_{d}\right)\left(\frac{\tilde{\lambda}}{1+r_{b}^{*}} R-\lambda C\right)
$$

Cash in Advance, Separating Case 3 Can it be optimal for the seller to ask for a payment that is only acceptable to unreliable firms when using cash in advance? No, because under this payment term, there is no commitment problem on the buyer side. Hence the two types of buyers behave exactly the same way. In particular, they have the same participation constraint.

Cash in Advance, Separating Case 4 Suppose that a reliable seller does not prefer cash in advance. Can it be profitable for an unreliable seller to pick cash in advance anyways, thereby revealing her type? Then, the buyer knows that she is dealing with an unreliable seller and the participation constraint becomes:

$$
\mathrm{E}\left[\Pi_{B}^{C I A, S}\right]=\lambda R-\left(1+r_{b}^{*}\right) P^{C I A, S}
$$


The unreliable seller then picks the optimal payment $P^{C I A, S}=\frac{\lambda}{1+r_{b}^{*}} R$, delivering expected profits of:

$$
\mathrm{E}\left[\Pi_{U S}^{C I A, S}\right]=\left(1+r_{d}\right)\left(\frac{\lambda}{1+r_{b}^{*}} R-\lambda C\right) .
$$

Suppose the reliable seller does not choose cash in advance (our starting point above). Then, a sufficient condition for the unreliable seller not to deviate and choose cash in advance is that expected profits of a reliable seller in the pooling case weakly dominate expected profits of an unreliable seller in the separating case. This is because an unreliable seller always has strictly larger expected profits under pooling than a reliable seller (as long as $\lambda<1$ ), as $\mathrm{E}\left[\Pi_{U S}^{C I A, P}\right]>\mathrm{E}\left[\Pi_{R S}^{C I A, P}\right]$. A sufficient condition to exclude the separating case is thus:

$$
\mathrm{E}\left[\Pi_{R S}^{C I A, P}\right] \geq \mathrm{E}\left[\Pi_{U S}^{C I A, S}\right] .
$$

Plugging in from equations (14) and (15) and rearranging delivers:

$$
R>\frac{1+r_{b}^{*}}{\eta} C
$$

If this condition holds, we can rule out Case 4. The condition is more demanding than condition (13). For example, taking correspondent parameters $\eta=0.8$ and $1+r_{b}^{*}=1.025$, would require a markup of at least 1.28 to rule out the separating case. It is quite easy though to tighten the condition in a realistic way by introducing an additional contract enforcement cost $\delta$ as in Schmidt-Eisenlohr (2013). With the additional enforcement cost, condition (16) becomes $R>\frac{1+r_{b}^{*}}{\eta} \frac{1-\lambda}{1-\lambda(1-\delta)} C$. Now, assume a small enforcement cost of $\delta=0.05$. That is, when a contract needs to be enforced in court, the firm that enforces the contract has to pay 5 percent of the amount that it recovers (for cash in advance, this is $R$ ). In addition, suppose that $\lambda=0.8$. Then, the required markup to rule out the separating case falls to 1.07. If $\delta>0.071$, then the condition always holds, even in the absence of a positive markup over marginal costs $(\mu=1)$.

To summarize, Cases 2 and 3 are never optimal for the seller, while Cases 1 and 4 can be excluded under relatively weak conditions. 


\section{B.3 Micro Foundation: A Learning Model}

In this section, we discuss an example of a learning model that can micro-found the dynamics discussed in section 2. The below exposition is based on Monarch and Schmidt-Eisenlohr (2018) and Araujo et al. (2016). ${ }^{1}$ We use the same setup as in the baseline model with two types of firms: reliable and unreliable. $\lambda$ and $\lambda^{*}$ now reflect the probability that the seller or buyer do not have an opportunity to cheat in a given period. Let $\hat{\eta}$ denote the population mean of reliable firms.

Bayesian updating Initially, a seller believes (correctly) that the probability a buyer is reliable is equal to the population mean, $\widehat{\eta} .^{2}$ Every period that a relationship survives, the seller updates her belief about the buyer according to Bayes' rule. A successful interaction signals that the buyer is either reliable or did not have an opportunity to cheat. Learning is therefore not instantaneous but takes time. However, learning is the fastest initially, as the probability that the trading partner is unreliable is the highest then.

If a seller has successfully sold to a buyer for $k$ periods, the posterior probability that the buyer is reliable can be derived as:

$$
\eta_{k}=\frac{\widehat{\eta}}{\widehat{\eta}+(1-\widehat{\eta}) \lambda^{k}}
$$

Importantly, the probability only changes with the length of time that a seller has been selling to the same buyer. It is easy to see that for large $k, \eta_{k}$ converges to 1 ; that is, the seller is almost certain that the buyer is reliable. To shed further light on this, we can take the derivative of $\eta_{k}$ with respect to $k$ :

$$
\frac{\partial \eta_{k}}{\partial k}=-\ln (\lambda) \hat{\eta}(1-\hat{\eta})\left(\frac{1}{\hat{\eta}+(1-\hat{\eta}) \lambda^{k}}\right)^{2} \lambda^{k}>0
$$

Not surprisingly, this derivative is always positive. That is, with every successful interaction, the seller's belief about the buyer's reliability improves. Now, taking the second derivative delivers:

$$
\frac{\partial^{2} \eta_{k}}{\partial k^{2}}=-(\ln (\lambda))^{2} \hat{\eta}(1-\hat{\eta}) \lambda^{k}\left[\frac{1}{\widehat{\eta}+(1-\hat{\eta}) \lambda^{k}}\right]^{2} \frac{\hat{\eta}-(1-\hat{\eta}) \lambda^{k}}{\hat{\eta}+(1-\hat{\eta}) \lambda^{k}},
$$

\footnotetext{
${ }^{1}$ See also Antràs and Foley (2015) and Macchiavello and Morjaria (2015) for similar setups.

${ }^{2}$ In this section, we drop the star superscript for buyers.
} 
which is smaller than zero for all $k$ if

$$
\hat{\eta}>\frac{\lambda}{1+\lambda}
$$

That is, as long as condition (20) holds, the second derivative of the belief with respect to $k$ is negative and the learning speed declines over time. Below, we present a graphical example on how learning looks like in this environment where we pick $\hat{\eta}$ such that condition (20) holds.

Figure B.3. Bayesian Learning: Level of Belief

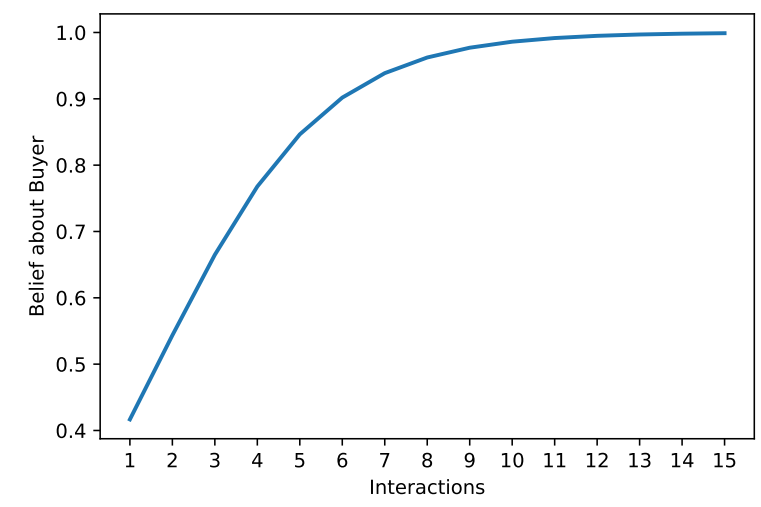

Notes: This figure illustrates the learning process in our example. Parameters are: $\hat{\eta}=0.3$ and $\lambda=0.6$.

Figure B.4. Bayesian Learning: Speed of Learning

A: First Difference of Belief

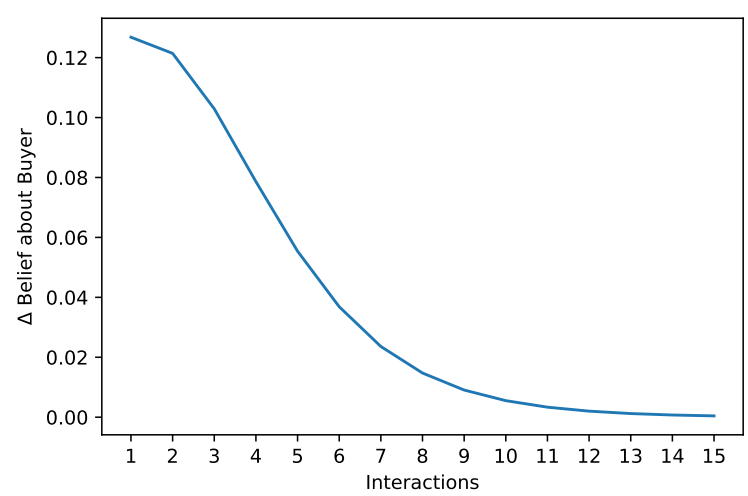

B: Second Difference of Belief

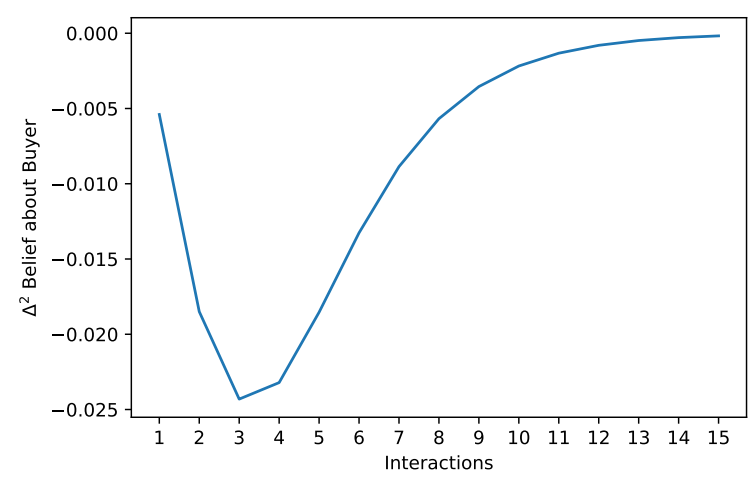

Notes: This figure illustrates the speed of learning in our example. Panel A shows the first difference in the belief about the buyer. Parameters are: $\hat{\eta}=0.3$ and $\lambda=0.6$.

The above discussion showed how learning about the buyer works when transactions are 
done with trade credit and the buyer has an incentive to deviate from the contract. To generate two-sided learning in this setup, there also needs an opportunity to deviate for the seller under trade credit. This could be modeled by following Antràs and Foley (2015) and allowing the seller to default on the bank loan that she draws to pre-finance production costs. In that case, if defaults to the bank are public information, the buyer learns about the seller even in the case of trade credit. The reverse mechanism would hold for the seller learning about the buyer with cash in advance.

\section{B.4 Pooling and separating cases - Buyer Bargaining Power}

For the Neutral Bargaining solution, we also need to understand the optimal payment choice when the buyer makes the decision, that is, when the buyer has all bargaining power. For this reason, we analyze the separating cases again in this alternative setting. Consider the following four cases:

1. The buyer offers a payment that is only accepted by unreliable sellers under trade credit.

2. The reliable buyer chooses cash in advance, but the unreliable buyer chooses trade credit.

3. The buyer offers a payment that is only accepted by unreliable sellers under cash in advance.

4. The reliable buyer chooses trade credit, but the unreliable buyer chooses cash in advance.

Trade Credit - pooling case Under the pooling case, expected profits are given by:

$$
\begin{aligned}
\mathrm{E}\left[\Pi_{S}^{T C, P}\right] & =\tilde{\lambda}^{*} P^{T C, P}-\left(1+r_{b}\right) C \\
\mathrm{E}\left[\Pi_{R B}^{T C, P}\right] & =R-P^{T C, P} \\
\mathrm{E}\left[\Pi_{U B}^{T C, P}\right] & =R-\lambda^{*} P^{T C, P}
\end{aligned}
$$

The buyer sets the payment to $P_{B}^{T C, P}=\frac{1+r_{b}}{\tilde{\lambda}^{*}} C$, implying expected profits of:

$$
\begin{aligned}
\mathrm{E}\left[\Pi_{R B}^{T C, P}\right] & =R-\frac{1+r_{b}}{\tilde{\lambda}^{*}} C, \\
\mathrm{E}\left[\Pi_{U B}^{T C, P}\right] & =R-\frac{\lambda^{*}\left(1+r_{b}\right)}{\tilde{\lambda}^{*}} C .
\end{aligned}
$$


Trade Credit, Separating Case 1 Can it be optimal for the buyer to offer a payment under trade credit that is only acceptable for unreliable sellers? No, because under trade credit expected profits and thus the participation constraint are the same for reliable and unreliable sellers. This is the case because there is no commitment problem on the seller side under trade credit.

Trade Credit, Separating Case 2 Suppose that a reliable buyer does not prefer trade credit. Can it be profitable for an unreliable buyer to pick trade credit anyways, thereby revealing her type? Then, the seller knows that she is dealing with an unreliable buyer and the participation constraint becomes:

$$
\mathrm{E}\left[\Pi_{S}^{T C, S}\right]=\lambda^{*} P^{T C, S}-\left(1+r_{b}\right) C
$$

Now, the buyer needs to pay $P^{T C, S}=\frac{1+r_{b}}{\lambda^{*}} C$, and expected profits become:

$$
\mathrm{E}\left[\Pi_{U B}^{T C, S}\right]=R-\left(1+r_{b}\right) C
$$

A sufficient condition to exclude the separating case is $\mathrm{E}\left[\tilde{\Pi}_{R B}^{T C, P}\right] \geq \mathrm{E}\left[\tilde{\Pi}_{U B}^{T C, S}\right]$, because $\mathrm{E}\left[\tilde{\Pi}_{U B}^{C I A, P}\right]=$ $\mathrm{E}\left[\tilde{\Pi}_{R B}^{C I A, P}\right] \geq \mathrm{E}\left[\tilde{\Pi}_{R B}^{T C, P}\right]$. The expected profits of an unreliable buyer in the separating case under trade credit are smaller than her expected profits in the pooling case. However, they are larger than the expected profits of a reliable firm under trade credit in the pooling case. Hence, it is not straightforward to derive parameter constraints under which the above sufficient condition that rules out this separating case in the baseline model holds.

However, we can derive such parameter constraints in a slightly extended version of the model. Consider again the extension in Schmidt-Eisenlohr (2013), where the firm that enforces the contract has to pay an enforcement $\operatorname{cost} \delta$ (again proportional to the recovery amount; with trade credit, this is $P^{T C}$ ). Then, expected profits change to:

$$
\begin{aligned}
\mathrm{E}\left[\tilde{\Pi}_{R B}^{T C, P}\right] & =R-\frac{1+r_{b}}{\eta^{*}+\left(1-\eta^{*}\right)(1-\delta) \lambda^{*}} C, \\
\mathrm{E}\left[\tilde{\Pi}_{U B}^{T C, S}\right] & =R-\frac{1+r_{b}}{1-\delta} C .
\end{aligned}
$$


This condition holds if:

$$
\delta \geq \frac{1-\eta^{*}-\left(1-\eta^{*}\right) \lambda^{*}}{1-\left(1-\eta^{*}\right) \lambda^{*}}
$$

Taking our parameters from before. If $\eta^{*}=0.8$ and $\lambda^{*}=0.8, \delta$ has to be greater or equal to 4.8 percent of the recovery value $(\delta \geq 0.048)$ to exclude Case 2.

Cash in Advance - pooling case Under cash in advance, expected profits are given by:

$$
\begin{aligned}
& \mathrm{E}\left[\Pi_{B}^{C I A, P}\right]=\tilde{\lambda} R-\left(1+r_{b}^{*}\right) P^{C I A, P}, \\
& \mathrm{E}\left[\Pi_{R S}^{C I A, P}\right]=P^{C I A, P}-C, \\
& \mathrm{E}\left[\Pi_{U S}^{C I A, P}\right]=P^{C I A, P}-\lambda C .
\end{aligned}
$$

In the pooling case, the buyer makes the reliable seller indifferent by setting $P^{C I A, P}=C$, which implies expected profits of:

$$
\begin{aligned}
& \mathrm{E}\left[\Pi_{B}^{C I A, P}\right]=\tilde{\lambda} R-\left(1+r_{b}^{*}\right) C, \\
& \mathrm{E}\left[\Pi_{U S}^{C I A, P}\right]=(1-\lambda) C .
\end{aligned}
$$

Cash in Advance, Separating Case 3 The buyer could offer a payment that is only acceptable to unreliable sellers. Then the payment would be less than production costs, $C$, specifically $P^{C I A, S}=\lambda C$. Only a fraction of contracts that the buyer offers, $1-\eta$, would be accepted, as reliable sellers would reject it. Expected profits of a buyer are then:

$$
\mathrm{E}\left[\Pi_{B}^{C I A, S}\right]=(1-\eta) \lambda\left(R-\left(1+r_{b}^{*}\right) C\right)
$$

Combining equations (23) and (24) implies that pooling dominates if:

$$
\eta R>(1-(1-\eta) \lambda)\left(1+r_{b}^{*}\right) C
$$

If this condition holds, we can exclude Case 3. The condition is relatively weak. For example, with $\eta=0.8, \lambda=0.8$, and $r=1.025$, this condition holds as long as the markup $\mu=\frac{R}{C}$ is greater or equal to 1.08 . 
Cash in Advance, Separating Case 4 Can it be optimal for the unreliable buyer to choose cash in advance if the reliable buyer chooses trade credit? No, because expected profits under cash in advance are the same across both types of buyers, and unreliable buyer have larger expected profits under trade credit.

To summarize, Cases 1 and 4 are never optimal for the buyer, while Cases 3 can be excluded under relatively weak conditions. Finally, to derive a sufficient condition for Case 2 requires a small and realistic extension of the model that leads to a relatively weak condition.

\section{Additional Details on Markups Estimation}

In the model, markups for each seller and product vary at the level of buyers located in different destinations. In practice, however, the computation of markups at this level of disaggregation is unfeasible, because it imposes severe data requirements that cannot be satisfied when using information for multiple industries and markets. ${ }^{3}$ Hence, to test the predictions of the theory we shut down the seller's dimension, and compute markups at the seller-product level using the methodology proposed by De Loecker et al. (2016). The main advantage of this methodology is that it allows us to compute markups abstracting from market-level demand information. It only requires to assume that firms minimize cost for each product and that at least one input is fully flexible.

The starting point in De Loecker et al. (2016), is to consider the firm's cost minimization problem. After rearranging the first-order condition of the problem for any flexible input $V$, the markup of product $p$ produced by firm $i$ in year $y\left(\mu_{i p y}\right)$ can be computed as the ratio between the output elasticity of product $p$ with respect to the flexible input $V\left(\theta_{i p y}^{V}\right)$ and expenditure share of the flexible input $V$ (relative to the sales of product $\left.p ; s_{i p y}^{V} \equiv P_{i p y}^{V} V_{i p y} / P_{i p y} Q_{i p y}\right):{ }^{4}$

$$
\underbrace{\mu_{i p y}}_{\text {Markup }} \equiv \frac{P_{i p y}}{M C_{i p y}}=\frac{\theta_{i p y}^{V}}{s_{i p y}^{V}},
$$

where $P\left(P^{V}\right)$ denotes the price of output $Q$ (input $\left.V\right)$, and $M C$ is marginal cost. While the

\footnotetext{
${ }^{3}$ Deriving markups at the buyer-seller-product level requires either detailed market or production information at the level of buyers and products. These data requirements are rarely fulfilled. A notable exception is CajalGrossi et al. (2019), who uses detailed information for the Bangladeshi garment industry to derive markups at the buyer-seller-product level.

${ }^{4}$ The derivation of (25) assumes that multi-product firms are equivalent to a collection of single-product firms; thus, this setup does not allow for economies of scope in production. Below, we show that our results also hold for single-product firms.
} 
numerator of equation (25) - the input-output elasticity of product $p$ - needs to be estimated, the denominator is directly observable in our data. Next, we explain the procedure we follow for deriving each of these elements.

Input-output elasticity. To estimate the input-output elasticities, we specify production functions for each product $p$ using labor $(L)$, capital $(K)$, and materials $(M)$ as production inputs:

$$
Q_{i p y}=\Omega_{i t} F\left(K_{i p y}, L_{i p y}, M_{i p y}\right)
$$

where $Q$ is physical output, and $\Omega$ denotes firm's productivity. There are three important assumptions on equation (26). First, the production function is product-specific, which implies that single and multi-product firms use the same technology to produce a given product. However, second, productivity is firm-specific. Finally, as is standard in the estimation of production functions, we assume Hicks-Neutrality, so that $\Omega$ is log-additive.

The estimation of (26) follows De Loecker et al. (2016) in using the subset of single-product firms to identify the coefficients of the production function. ${ }^{5}$ Different from them, we deflate inputs expenditure with firm-specific input price indexes to avoid that the so-called input price bias affect the estimated coefficients (see De Loecker and Goldberg, 2014). ${ }^{6}$

Our baseline specification assumes a Cobb-Douglas production function, and allows for the presence of a log-additive non-anticipated shock $(\varepsilon) .{ }^{7}$ Taking logs to $(26)$, we obtain

$$
q_{i p y}=\alpha_{k}^{p} k_{i p y}+\alpha_{l}^{p} l_{i p y}+\alpha_{m}^{p} m_{i p y}+\omega_{i y}+\varepsilon_{i p y}
$$

The estimation of (27) follows Ackerberg et al. (2015) (henceforth, ACF), who extend the methodology proposed by Olley and Pakes (1996) and Levinsohn and Petrin (2003) to control for the endogeneity of firms' inputs choice -which is based on the actual level of firms'

\footnotetext{
${ }^{5}$ The reason for using only single-product firms is that, for this set of firms, there is no need of specifying how inputs are distributed across individual outputs.

${ }^{6}$ In De Loecker et al. (2016), input prices are not available in their sample of Indian firms, so they implement a correction to control for input price variation. We discuss below the construction of the input price index we use in our sample of Chilean firms.

${ }^{7} \mathrm{~A}$ shortcoming of the Cobb-Douglas specification is that it assumes that input-output elasticities are constant across firms and over time. On the other hand, the Cobb-Douglas specification is widely used, allowing for a more direct comparison of our results with other estimates in the literature. In the robustness checks section, we present results with derived using a more flexible Translog production function, which allows for different types of complementarities among production inputs. Results are quantitatively similar, although coefficients are slightly less precisely estimated than with the Cobb-Douglas baseline.
} 
productivity. ${ }^{8}$ To identify the coefficients of the production function, we build moments based on the productivity innovation $\xi$. We specify the following process for the law of motion of productivity:

$$
\omega_{i y}=g\left(\omega_{i y-1}, d_{i y-1}^{x}, d_{i y-1}^{i}, d_{i y-1}^{x} \times d_{i y-1}^{i}, \hat{s}_{i y-1}\right)+\xi_{i y}
$$

where $d^{x}$ is an export dummy, $d^{i}$ is a categorical variable for periods with positive investment, and $\hat{s}$ is the probability that the firm remains single-product. The endogenous productivity process (28) follows the corrections suggested by De Loecker (2013), allowing firms' productivity path to be affected by past exporting and investment decisions. In addition, it follows De Loecker et al. (2016) in including the probability of remaining single-product to correct for the bias that results from firm switching non-randomly from single to multi-product.

The first step of the ACF procedure involves expressing productivity in terms of observables. To do so, we use inverse material demand $h_{y}(\cdot)$ as in Levinsohn and Petrin (2003) to proxy for unobserved productivity, and estimate expected output $\phi_{y}\left(k_{i y}, l_{i y}, m_{i y} ; \mathbf{x}_{i y}\right)$ to remove the unanticipated shock component $\varepsilon_{i y}$ from (27). ${ }^{9}$ Then, the ACF procedure exploits this representation to express productivity as a function of data and parameters: $\omega_{i y}(\boldsymbol{\alpha})=$ $\hat{\phi}_{y}(\cdot)-\alpha_{k} k_{i y}-\alpha_{l} l_{i y}-\alpha_{m} m_{i y}$, and form the productivity innovation $\xi_{i y}$ from (28) as a function of the parameters $\boldsymbol{\alpha}$. The second step of ACF routine forms moment conditions on $\xi_{\text {iy }}$ to identify all parameters $\boldsymbol{\alpha}$ through GMM:

$$
\mathbb{E}\left(\xi_{i y}(\boldsymbol{\alpha}) \cdot \mathbf{Z}_{i y}\right)=0
$$

where $\mathbf{Z}_{i y}$ contains lagged materials, labor, and capital, and current capital. Once the parameters are estimated, the input-output elasticities are recovered for each product as $\theta_{i p y}^{V} \equiv$ $\partial \ln Q_{i p y} / \partial \ln V_{i p y}$. For the Cobb-Douglas case, $\theta_{i p y}^{V}=\alpha_{V}^{p}$, so that the input-output elasticity is constant for all plants producing a given product $p .^{10}$

\footnotetext{
${ }^{8} \mathrm{ACF}$ show that the labor elasticity is in most cases unidentified by the two-stage method of Olley and Pakes (1996) and Levinsohn and Petrin (2003).

${ }^{9}$ The vector $\mathbf{x}_{i y}$ includes other variables affecting material demand, such as time and product dummies. We approximate $\phi_{y}(\cdot)$ with a full second-degree polynomial in capital, labor, and materials.

${ }^{10}$ In the Translog case, the input elasticities $\theta_{i p y}^{V}$ depend on the firms' input use. This information is directly observed in single-product firms. For multi-product firms, we derive inputs' use by each output following the same procedure we apply for computing the expenditure share of the inputs $s_{i p y}^{V}$ explained next.
} 
Implementation. To derive markups, we use materials as the relevant flexible input to compute the output elasticity. While in principle, labor could also be used to compute markups, the existence of long-term contracts and firing costs make firms less likely to adjust labor after the occurrence of shocks. The second component needed in (25) to compute markups is the expenditure share, which requires to identify the assignment of firms' inputs across outputs produced by the firm. To implement this, we follow Garcia-Marin and Voigtländer (2019) and exploit a unique feature of our data: ENIA provides information on total variable costs (labor cost and materials) for each product produced by the firms. We use this information to proxy for product-specific input use assuming that inputs are used approximately in proportion to the variable cost shares, so that the value of materials' expenditure $M_{i p y}=P_{i p y}^{V} V_{i p y}$ is computed as

$$
\tilde{M}_{i p y}=\rho_{i p y} \cdot \tilde{M}_{i y}, \quad \text { where } \quad \rho_{i p y}=\frac{T V C_{i p y}}{\sum_{j} T V C_{i p y}}
$$

Finally, we compute the expenditure share dividing the value of material inputs by productspecific revenues, which are observed in the data.

Input Price Index. To avoid that the production function parameters estimate are affected by input price bias (see De Loecker and Goldberg, 2014, for details), we deflate materials' expenditure using firm-specific price indexes. The construction the input price deflator involves five steps. First, we define the unit value of input $p$ purchased by firm $i$ in period $y$ as $P_{i p y}=V_{i p y} / Q_{i p y}$, where $V_{i p y}$ denotes input $p$ value, and $Q_{i p y}$ denotes the corresponding quantity purchased. Next, we calculate the (weighted) average unit value of input $p$ across all firms purchasing the input in year $y$. Then, for each firm, we compute the (log) price deviation from the (weighted) average for all the inputs purchased by the firm in year $y$. The next step involves averaging the resulting price deviations at the firm level, using inputs' expenditure as weight. ${ }^{11}$ Finally, we anchor the resulting average firm-level input price deviation to aggregate (4-digit) input price deflators provided by the Chilean statistical agency. Therefore, the resulting input price index reflects both, changes in the aggregate input price inflation, as well as firm-level heterogeneity in the price paid by firms for their inputs.

\footnotetext{
${ }^{11}$ Note that up to this point we have derived a unit-free input price index, that can be interpreted as the average firm-level input price deviation from the average. However, this price index will fail to detect aggregate changes in input prices.
} 
Average Markups by 2-digit industries Table C.1 presents the estimated markups at the level of 2-digit industries.

Table C.1. Estimated Markups

\begin{tabular}{lccc}
\hline \hline Product & Mean & Median & St. Deviation \\
\hline Food and Beverages & 1.344 & 1.2189 & 0.5711 \\
Textiles & 1.581 & 1.4491 & 0.6420 \\
Apparel & 1.267 & 1.2261 & 0.4649 \\
Wood and Furniture & 1.123 & 1.0070 & 0.4455 \\
Paper & 1.273 & 1.1214 & 0.5687 \\
Basic Chemicals & 1.389 & 1.2236 & 0.6555 \\
Plastic and Rubber & 1.241 & 1.0924 & 0.5305 \\
Non-Metallic Manufactures & 1.779 & 1.5555 & 0.8774 \\
Metallic Manufactures & 1.316 & 1.0241 & 0.7156 \\
Machinery and Equipment & 1.146 & 1.0102 & 0.4986 \\
\hline Total & 1.318 & 1.178 & 0.583 \\
\hline \hline
\end{tabular}

Notes: This table reports the average markup by aggregate sector for the sample Chilean exporters over the period 2003-2007.

\section{Data Appendix}

In this appendix we provide additional detail on the construction of the dataset we use in the main empirical analysis. In the following, we briefly discuss the procedure we follow to combine the production data in ENIA with the customs level data at the firm-product level. We also explain the data cleaning procedure we apply to avoid inconsistencies.

The main issue in combining data from Customs and ENIA at the firm-product level is that products are classified using different nomenclatures in both datasets: ENIA classifies products according to the Central Product Classification (CPC), while the Chilean Customs Administration classifies products according to the Harmonized System (HS). To deal with this issue, we follow several steps. First, we use the United Nations' correspondence tables to determine the list of HS products that could potentially be matched to each CPC product in ENIA. ${ }^{12}$ We then merge the resulting dataset with customs data at the firm-HS-year level. This procedure results in two cases: (i) All exported HS products in customs within a firm-year pair are merged to ENIA, and (ii) Only a fraction (or none) of the exported products are matched to

\footnotetext{
${ }^{12}$ The correspondence table establishes matches between 5-digit CPC and 6-digit HS products. This level of disaggregation corresponds to 783 5-digit CPC products.
} 
ENIA within a firm-year pair. For the latter cases, whenever there is concordance within 4-digit HS categories, we manually merge observations based on HS and CPC product descriptions. Borderline cases (no clear connection between product descriptions), as well as cases with no concordance at the 4-digit HS level are dropped.

In addition, to ensure a consistent dataset, we follow several steps. In particular, we exclude: (i) firm-year observations that have zero values for raw materials expenditure or employment, (ii) firm-product-year observations with zero or missing sales, product quantities, or with extreme values for markups (above the 98 th or below the 2nd percentiles, or with large unplausible variations in markups within firm-products), and (iii) destination-year pairs with extreme values of the real borrowing rates, to avoid the influence of extreme values resulting from inflationary or deflationary episodes. ${ }^{13}$ The final dataset consists of 608,588 firm-product-destinations-days observations, out of which approximately two-thirds correspond to relationships (defined at the firm-product-destination level) that started before 2003. The sample represents $80.5 \%$ of the value of Chilean (non-copper) exports over the period 2003-2007.

\section{E Additional Results and Robustness Checks}

\section{E.1 Markups and the use of Cash in Advance and Letters of Credit Contracts.}

The main analysis shows that the use of trade credit increases with markups and relationship length. There, figure 3 indicates that the increasing use of trade credit is mostly at the expense of cash in advance, while letter of credit use is relatively stable in relationship length. In this subsection, we show that also the relationship between trade credit and markups is mirrored by a corresponding relationship between cash in advance and markups. The use of letters of credits, in contrast, does not change much with markups.

Figure E.1 shows that the use of cash in advance declines in markups, with the effect being stronger for destinations with relatively high borrowing rates (panels B and $\mathrm{C}$ ). The figure is almost the exact mirror image of figure 2, suggesting that firms with a higher markup increase their use of trade credit at the expense of cash in advance.

\footnotetext{
${ }^{13}$ In practice, this correction drops country-years with real borrowing rates above $35 \%$, and below $-4 \%$.
} 
Figure E.1. Cash in Advance Share and Markups

A. Full Sample

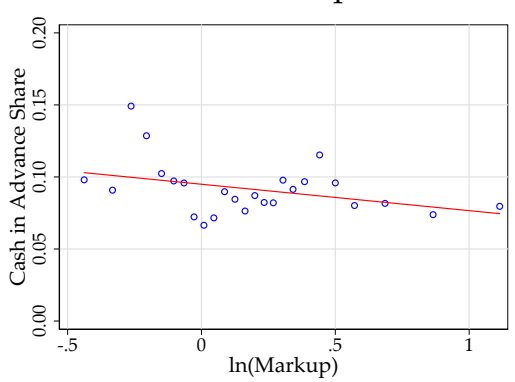

B. High Interest Rate Destination

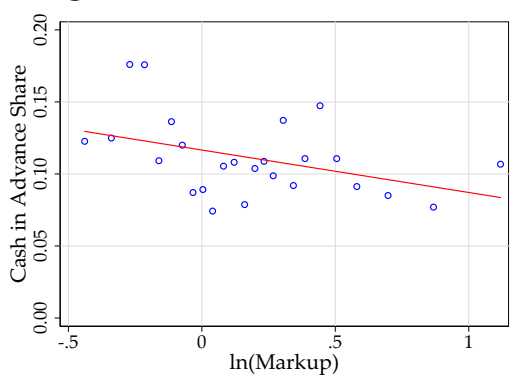

C. Low Interest Rate Destination

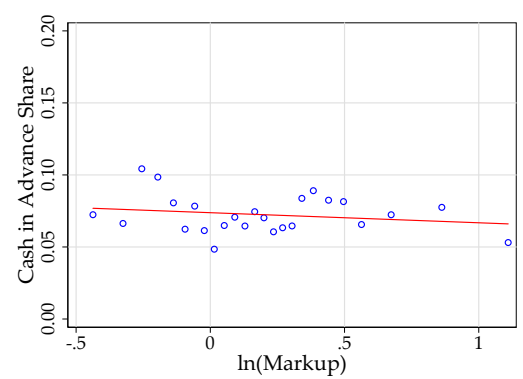

Notes: The figure shows binscatter plots of the cash in advance share against firm-product markups (in logs), computed as in De Loecker et al. (2016). Panel A shows results for the full sample, Panels B and C split the sample and use data for high and low borrowing rates destination, respectively. All figures control for destination-year fixed-effects.

Figure E.2 shows that, in comparison to trade credit and cash in advance, the use of letters of credit is relatively unresponsive to markups, both in the full sample (panel A), and when splitting the sample for high and low interest rate destinations (panels B and $\mathrm{C}$ ).

Figure E.2. Letters of Credit Share and Markups

A. Full Sample

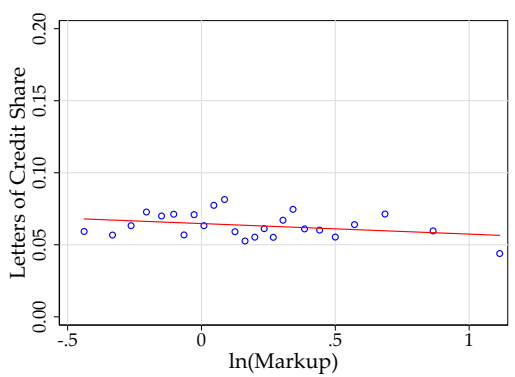

B. High Interest Rate Destination

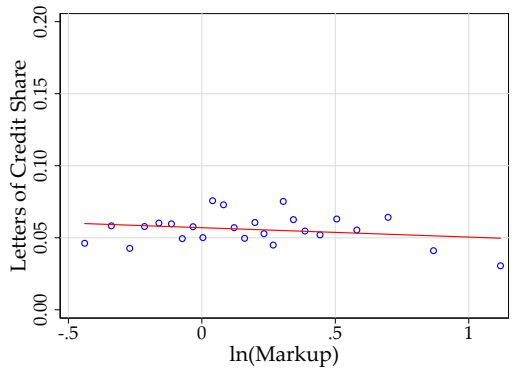

C. Low Interest Rate Destination

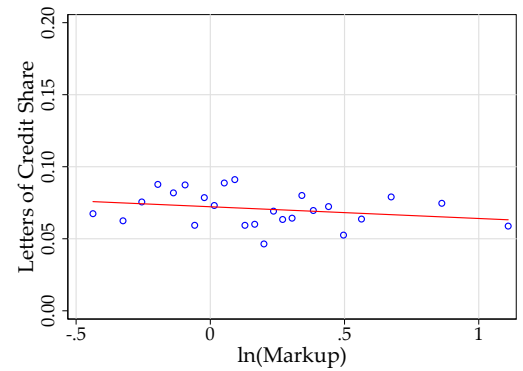

Notes: The figure shows binscatter plots of the letter of credit share against firm-product markups (in logs), computed as in De Loecker et al. (2016). Panel A shows results for the full sample, Panels B and C split the sample and use data for high and low borrowing rates destination, respectively. All figures control for destination-year fixed-effects.

\section{E.2 Additional Robustness Checks}

In this section, we provide details on the robustness checks mentioned in section 5.4: 
Sample with Low Export Participation. Table E.1 provides further evidence on the positive effect of markups on trade credit choice. Markups in our sample correspond to averages across all customers. Thus, even if firms charge higher markups on transactions involving trade credit, the resulting bias should be relatively modest, especially for firm-products with welldiversified sales across markets. In this section we build on this insight and show that the results are very similar when restricting the sample to the set of firms with relatively low export participation.

Table E.1 report results for three different subsamples of firms, according to their overall export share. We begin with the sample of exporters with at most $50 \%$ export share, and then move to plants with less than 25\%, and $10 \%$ export share. As can be seen, when using the baseline markup measure, coefficients lie between .015 and .035 - although the coefficient is less precisely estimated as we increasingly restrict the sample. Results in columns 4 through 6 replicate the exercise using markups fixed at their initial value within firm-products, while columns 7 through 9 use the average markup within firm-products. In all these cases, coefficients are positive and highly significant, strengthening the evidence on the positive effect of markups on trade credit choice.

Table E.1. Trade Credit Share and Markup - Sample of Firms with Low Export Intensity

\begin{tabular}{|c|c|c|c|c|c|c|c|c|c|}
\hline \multirow{3}{*}{$\begin{array}{l}\text { Markup measure } \\
\text { Export share }\end{array}$} & \multirow{3}{*}{$\begin{aligned} & (1) \\
< & 50 \%\end{aligned}$} & \multirow{3}{*}{$\begin{array}{c}(2) \\
\text { Baseline }- \\
<25 \%\end{array}$} & \multirow{2}{*}{ (3) } & \multirow{2}{*}{\multicolumn{3}{|c|}{$\begin{array}{l}(5) \\
\text { Initial Markup }{ }^{(6)}\end{array}$}} & \multirow{2}{*}{\multicolumn{3}{|c|}{$\begin{array}{l}(7) \\
\quad \text { Average Markup } \\
\end{array}$}} \\
\hline & & & & & & & & & \\
\hline & & & $<10 \%$ & $<50 \%$ & $<25 \%$ & $<10 \%$ & $<50 \%$ & $<25 \%$ & $<10 \%$ \\
\hline \multirow[t]{2}{*}{$\ln ($ markup $)$} & $.0351 * * *$ & .0149 & .0259 & $.0684^{* * *}$ & $.0910^{* * *}$ & $.105^{* * *}$ & $.107^{* * *}$ & $.113^{* * *}$ & $.0774^{* *}$ \\
\hline & $(.00906)$ & $(.0120)$ & $(.0193)$ & $(.0179)$ & $(.0212)$ & $(.0287)$ & $(.0254)$ & $(.0295)$ & $(.0358)$ \\
\hline \multirow{2}{*}{$\ln ($ employment $)$} & $-.0309 * * *$ & -.00327 & -.0147 & $-.0313^{* * *}$ & -.00364 & -.0142 & $-.0309 * * *$ & -.00315 & -.0147 \\
\hline & $(.00762)$ & $(.0115)$ & $(.0204)$ & $(.00764)$ & $(.0115)$ & $(.0203)$ & $(.00763)$ & $(.0115)$ & $(.0203)$ \\
\hline HS8 FE & $\checkmark$ & $\checkmark$ & $\checkmark$ & $\checkmark$ & $\checkmark$ & $\checkmark$ & $\checkmark$ & $\checkmark$ & $\checkmark$ \\
\hline Firm FE & $\checkmark$ & $\checkmark$ & $\checkmark$ & $\checkmark$ & $\checkmark$ & $\checkmark$ & $\checkmark$ & $\checkmark$ & $\checkmark$ \\
\hline Country-Year FE & $\checkmark$ & $\checkmark$ & $\checkmark$ & $\checkmark$ & $\checkmark$ & $\checkmark$ & $\checkmark$ & $\checkmark$ & $\checkmark$ \\
\hline Observations & 39,889 & 27,821 & 14,745 & 39,889 & 27,821 & 14,745 & 39,889 & 27,821 & 14,745 \\
\hline $\mathrm{R}^{2}$ & .442 & .487 & .540 & .442 & .488 & .540 & .442 & .488 & .540 \\
\hline
\end{tabular}

Notes: The table reports the coefficient estimates from equation (22). All regressions are run at the firmproduct-destination level (with products defined at the HS8-level). Trade credit shares are computed as the ratio of the FOB value of trade credit transactions to the FOB value of all export transactions over a year. Markups are computed at the firm-product level. Standard errors (in parentheses) are clustered at the firmproduct level. Key: *** significant at $1 \% ; * * 5 \% ; * 10 \%$.

Translog Markups. One potential concern for our results is that they rely on the correct estimation of markups. Our baseline markup measures are computed using input-output elasticities derived from a Cobb-Douglas production function (see equation 25). One shortcoming 
of this specification is that it imposes constant elasticities across all firms producing the same product. If firms with higher trade credit use have a lower input-output elasticity, then imposing constant input elasticities would lead us to overestimate the positive relationship between trade credit and markups. To analyze whether the Cobb-Douglas specification drives our results, in table E.2, we present results using markups derived from the more flexible translog production function, which allows for a rich set of interactions between the different inputs. ${ }^{14}$ Columns 1 through 3 of table E.2 estimate the baseline level regression using average translog markups. As in the baseline case, the trade credit share shows a strong positive relationship with markups. The coefficients in table E.2 are very similar and not statistically different than the baseline case (compare them with the corresponding coefficients in table 2). This suggests that input elasticities do not systematically vary with trade credit across firm-products.

Table E.2. Markups and Trade Credit Share: Alternative Markup Proxies

\begin{tabular}{l|ccc|ccc}
\hline \hline Markup Proxy: & \multicolumn{3}{|c|}{ Translog Markup - } & \multicolumn{3}{|c}{ Avg. Price-Cost Margin - } \\
& $(1)$ & $(2)$ & $(3)$ & $(4)$ & $(5)$ & $(6)$ \\
\hline $\ln$ (Markup) & $.0194^{* * *}$ & $.0175^{* * *}$ & $.0195^{* * *}$ & $.0165^{* *}$ & $.0170^{* * *}$ & .0135 \\
& $(.00451)$ & $(.00446)$ & $(.00493)$ & $(.00656)$ & $(.00656)$ & $(.0104)$ \\
\hline Firm-Destination FE & $\checkmark$ & $\checkmark$ & - & $\checkmark$ & $\checkmark$ & - \\
Year FE & - & $\checkmark$ & - & - & $\checkmark$ & - \\
HS8 FE & - & $\checkmark$ & $\checkmark$ & - & $\checkmark$ & $\checkmark$ \\
Firm FE & - & - & $\checkmark$ & - & - & $\checkmark$ \\
Destination-Year FE & - & - & $\checkmark$ & - & - & $\checkmark$ \\
\hline Observations & 91,337 & 91,337 & 91,337 & 91,337 & 89,618 & 89,618 \\
$\mathrm{R}^{2}$ & .664 & .665 & .368 & .665 & .666 & .367 \\
\hline \hline
\end{tabular}

Notes: The table reports the coefficient estimates from equation (22). All regressions are run at the firmproduct-destination level (with products defined at the HS8-level). Trade credit shares are computed as the ratio of the $\mathrm{FOB}$ value of trade credit transactions to the FOB value of all export transactions over a year. Markups in columns 1-3 are computed at the firm-product-year level; average price-cost margins in columns 4-6 are computed at the firm-product level (products are defined at the 5-digit CPC level). Standard errors (in parentheses) are clustered at the firm-product level. Key: ${ }^{* * *}$ significant at $1 \%$; $* *$ $5 \% ; * 10 \%$.

Average product margin. An additional proxy for markups that we can compute in our sample is product-level price-cost margins. ENIA reports the variable production cost per product, defined as the sum of raw material and direct labor costs involved in the production of each product. Product margins can be derived by dividing prices (unit values) over this reported measure of average variable cost. Note that the average variable cost is self-reported by

\footnotetext{
${ }^{14}$ We use a second-order Translog specification. In this case, materials input elasticity varies with the usage of all input, and is computed as $\theta_{i p y}^{M}=\alpha_{m}^{p}+2 \alpha_{m m}^{p} m_{i p y}+\alpha_{k m}^{p} k_{i p y}+\alpha_{l m}^{p} l_{i p y}$.
} 
managers, making the application of rules of thumb likely. Reported margins tend to align more closely with markups and other measures of profitability over longer periods. Consequently, we use firm-product average margins computed over all periods as an alternative measure of markups.

Figure E.3 shows binscatter plots for firm-product markups and sales-cost margins (with products defined at the HS-8 level), for the raw data (left panel), and averaging across observations within firm-product pairs (right panel). Both figures control for country-year fixed effects (that is, the figure plots the within plant-product variation that we exploit empirically). There is a remarkable positive relationship between markups and reported margins, suggesting that our markup estimates yield sensible information about the profitability of the products produced by the firm. This lends strong support to the markup-based methodology for backing out marginal costs by De Loecker et al. (2016). In addition, there seems to be a tighter relationship between markups and margins when both variables are averaged within firm-products. ${ }^{15}$ Consequently, we use firm-product average margins computed over all periods as an alternative measure of markups (see columns 4-6 in table E.2).

Columns 4 through 6 of table E.2 estimate our baseline level regression using the average price-cost margins. As can be seen, using margins as a proxy for markups does not affect our results qualitatively. Coefficients are similar to the baseline case, but standard errors are slightly larger, which is consistent with the more limited variation of the average margin measure (the unconditional standard deviation of average margins is about one-third smaller than in the Cobb-Douglas benchmark).

\footnotetext{
${ }^{15}$ One reason why both measures could be more correlated over longer periods of time is that the sales-cost margin measure relies on self-reported average variable cost. If managers measure product-level variable costs with error, then the sales-cost margin may be a poorer approximation of markups in the short run. However, if managers do not make systematic mistakes when reporting average variable costs, the measurement error cancels out when averaging over longer periods.
} 
Figure E.3. Firm-Product level Markup and Sales-Cost Margin

A. Levels

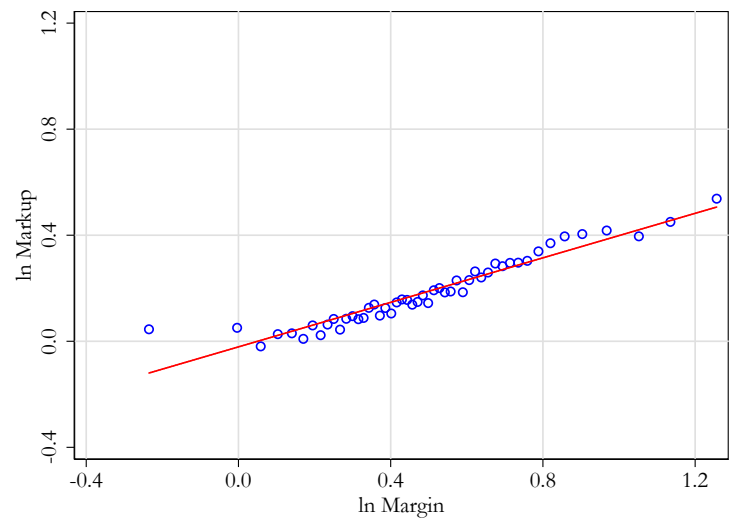

B. Averages within Firm-Years

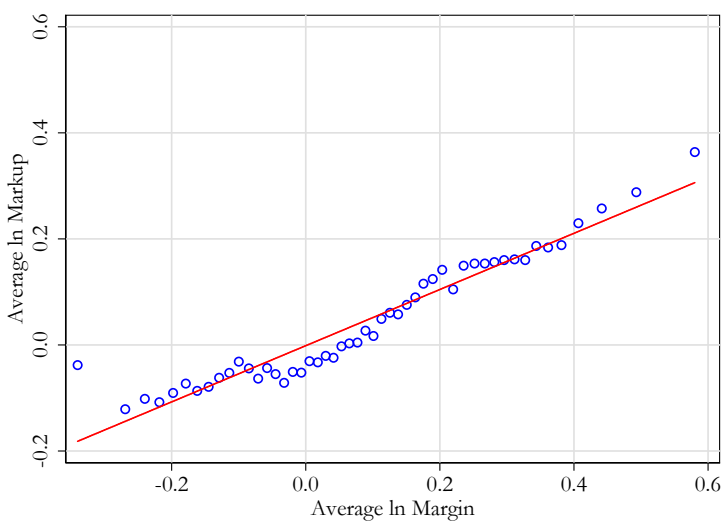

Notes: The figure plots a binscatters diagram for firm-product markups and sales-cost margins. All figures control for country-year fixed effects.

Censoring. The dependent variable we use to analyze the effect of markups on trade credit is a proportion with limited variation in the range 0-1. Since average trade credit is relatively high in our sample (around 90\% according to table 1), using the trade credit share as the main dependent variable limits the potential response of trade credit use to markups for firm-products with initially high trade credit use. In table E.3 we revisit the question on the magnitude of the markup mechanism using a logit transformation on the trade credit share, to pull out its variation over all of the real numbers. We run the following specification:

$$
\ln \left(\frac{\rho_{i j p y}}{1-\rho_{i j p y}}\right)=\beta_{1} \ln \left(\mu_{i p y}\right)+\gamma_{1} \ln \left(L_{i y}\right)+\delta_{i}+\delta_{p}+\delta_{j y}+\epsilon_{i j p y}
$$

where $\rho$ denotes the trade credit share. In this alternative specification, the marginal response of the trade credit share $\rho$ to markups is non-linear and varies with the amount of trade credit use. In particular, it can be shown that the effect of log-markups over the trade credit share can be computed as $\beta_{1} \times \rho_{\text {ijpy }} \times\left(1-\rho_{i j p y}\right)$. Plugging in the coefficients from table E.3, leads to an estimated implied trade credit share-markup elasticity of 0.040-0.042 (OLS), and 0.17-0.24 (IV) for firm-products with trade credit share equal to the mean (90 percent in our sample). This is about twice the magnitude of the baseline coefficients in columns 1 and 6 of table 2 . 
Table E.3. Logistic Trade credit Share Transformation

\begin{tabular}{lcccc}
\hline \hline Specification & $\begin{array}{c}\text { OLS } \\
(1)\end{array}$ & $\begin{array}{c}\text { OLS } \\
(2)\end{array}$ & $\begin{array}{c}\text { 2SLS } \\
(3)\end{array}$ & $\begin{array}{c}\text { 2SLS } \\
(4)\end{array}$ \\
\hline $\ln$ (Markup) & $.470^{* * *}$ & $.442^{* * *}$ & $1.852^{* * *}$ & $2.703^{* * *}$ \\
& $(.105)$ & $(.110)$ & $(.607)$ & $(.686)$ \\
$\ln ($ employment) & -.00498 & .0235 & .0414 & .0655 \\
& $(.103)$ & $(.112)$ & $(.117)$ & $(.130)$ \\
Implied Avg. Markup Semi-elasticity & 0.042 & 0.040 & 0.166 & 0.242 \\
\hline First-Stage F-Statistic & - & - & 161.7 & 185.4 \\
\hline Firm-Country FE & $\checkmark$ & - & $\checkmark$ & - \\
Year FE & $\checkmark$ & - & $\checkmark$ & - \\
HS8 FE & $\checkmark$ & $\checkmark$ & $\checkmark$ & $\checkmark$ \\
Firm FE & - & $\checkmark$ & - & $\checkmark$ \\
Country-Year FE & - & $\checkmark$ & - & $\checkmark$ \\
\hline Observations & 93,556 & 93,556 & 90,727 & 90,727 \\
$\mathrm{R}^{2}$ & .645 & .675 & .365 & .405 \\
\hline \hline
\end{tabular}

Notes: The table reports the coefficient estimates from equation (22) using a logistic transformation on the trade credit share as dependent variable. All regressions are run at the firm-product-destination level (with products defined at the HS8-level). Trade credit shares are computed as the ratio of the FOB value of trade credit transactions to the FOB value of all export transactions over a year. Standard errors (in parentheses) are clustered at the firm-product level. Key: ${ }^{* * *}$ significant at $1 \%$; ${ }^{* *} 5 \%$; ${ }^{*} 10 \%$.

Single-product firms. In order to estimate product-level and markups, we needed to assign inputs to individual outputs in multi-product plants. This is not needed in single-product plants, where inputs are used in the production of a single final product. Columns 1 through 3 in table E.4 use only the subset of single-product firms to estimate the relationship between markups and trade credit use following equation (22). Even though the sample is smaller, results for single-product plants remain statistically highly significant and quantitatively similar to the full sample, with a coefficient of 0.036-0.038.

Firm-level markups. An alternative strategy to determine the robustness of our results is to compute markups at the firm-level. As in the case of single-product firms, computing markups at the firm-level has the advantage that it avoids assigning inputs to individual outputs. Results in columns 4 through 6 in table E.4 show that coefficients remain quantitatively similar and stay statistically significant at the $1 \%$ level. 
Table E.4. Markups and Trade credit Share: Alternative Markup Proxies

\begin{tabular}{l|ccc|ccc}
\hline \hline Sample/Markup Measure: & \multicolumn{3}{|c|}{ - Single-Product Firms - } & \multicolumn{3}{c}{ - Firm-Level Markup - } \\
& $(1)$ & $(2)$ & $(3)$ & $(4)$ & $(5)$ & $(6)$ \\
\hline $\ln ($ Markup) & $.0358^{* * *}$ & $.0376^{* * *}$ & $.0384^{* * *}$ & $.0221^{* * *}$ & $.0225^{* * *}$ & $.0230^{* * *}$ \\
& $(.00726)$ & $(.00745)$ & $(.00782)$ & $(.00509)$ & $(.00510)$ & $(.00531)$ \\
$\ln$ Employment) & $-.0141^{* *}$ & $-.0158^{* * *}$ & -.0122 & .00538 & .00322 & .00366 \\
& $(.00586)$ & $(.00598)$ & $(.00747)$ & $(.00423)$ & $(.00441)$ & $(.00487)$ \\
\hline Firm-Destination FE & $\checkmark$ & $\checkmark$ & - & $\checkmark$ & $\checkmark$ & - \\
Year FE & - & $\checkmark$ & - & - & $\checkmark$ & - \\
HS8 FE & - & $\checkmark$ & $\checkmark$ & - & $\checkmark$ & $\checkmark$ \\
Firm FE & - & - & $\checkmark$ & - & - & $\checkmark$ \\
Destination-Year FE & - & - & $\checkmark$ & - & - & $\checkmark$ \\
\hline Observations & 44,596 & 44,596 & 44,596 & 93,118 & 93,118 & 93,118 \\
$\mathrm{R}^{2}$ & .688 & .719 & .384 & .660 & .690 & .369 \\
\hline \hline
\end{tabular}

Notes: The table reports the coefficient estimates from equation (22). All regressions are run at the firmproduct-destination level (with products defined at the HS8-level). Trade credit shares are computed as the ratio of the FOB value of trade credit transactions to the FOB value of all export transactions over a year. Markups in columns 1-3 are computed at the firm-product-year level; average price-cost margins in columns 4-6 are computed at the firm-product level (products are defined at the 5-digit CPC level). Standard errors (in parentheses) are clustered at the firm-product level. Key: *** significant at $1 \%$; ** $5 \% ; * 10 \%$.

Further Robustness Checks. We performed several additional robustness checks that are not reported in separate tables here but are available upon request. First, the descriptive evidence presented in section 4 suggests a non-linear relationship between markups and trade credit use in the raw data. However, when we included a quadratic markup term to the baseline regression, the coefficient - although negative - was typically small and statistically insignificant (t-statistic -0.20). In contrast, the linear markup term stayed positive, and its magnitude was very similar to the baseline linear specification. ${ }^{16}$ Second, we tested whether adding further controls affects the main relation between markups and trade credit. We began by adding the $\log$ FOB value of firm-product level exports to control for the size of the export shipments. The coefficient on the log FOB value was positive and statistically significant, but the markup coefficient stayed unchanged. Next, to test whether the existence of previous export relations could drive our results, we included the cumulative sum of the FOB value of all previous shipments of the same product to each destination. While the cumulative export coefficient turned positive and statistically significant, the markup coefficient did not change significantly, confirming our main finding.

\footnotetext{
${ }^{16}$ We also tested potential non-linearities using markup quintiles instead of quadratic terms. Results provide no evidence of a non-linear relation between markups and trade credit use.
} 
Alternative Measures of Relationship Length. In this section, we check the robustness of our result on trade credit use and relationship length, using alternative definitions of relationships. Table E.5 presents the results. Panel A proxies relationship length by the cumulative FOB sales value within a relationship. Table E. 5 shows that results are qualitatively similar to the baseline estimates in table 6 when using this alternative measure.

Table E.5. Relationship Length and Trade Credit Share: Alternative Measures

\begin{tabular}{|c|c|c|c|c|}
\hline & $(1)$ & $(2)$ & $(3)$ & $(4)$ \\
\hline \multicolumn{5}{|c|}{ Panel A. Cumulative FOB sales } \\
\hline $\ln$ (Cumulative FOB Sales) & $\begin{array}{c}.00270^{* * *} \\
(.00024)\end{array}$ & $\begin{array}{c}.00099^{* * *} \\
(.00024)\end{array}$ & $\begin{array}{c}.00121^{* * *} \\
(.00022)\end{array}$ & $\begin{array}{c}.00153^{* * *} \\
(.00045)\end{array}$ \\
\hline Sample & All & All & All & Balanced \\
\hline Firm-HS8-Country FE & Yes & Yes & Yes & Yes \\
\hline Country-Year FE & - & Yes & Yes & Yes \\
\hline Firm-HS8-Year FE & - & - & Yes & Yes \\
\hline Observations & 212,940 & 212,940 & 212,940 & 47,264 \\
\hline $\mathrm{R}^{2}$ & 0.675 & 0.682 & 0.728 & 0.723 \\
\hline \multicolumn{5}{|c|}{ Panel B. Country-Specific Relationships } \\
\hline $\log (\#$ Transactions $)$ & $\begin{array}{c}.0114^{* * *} \\
(.0022)\end{array}$ & $\begin{array}{c}.0101^{* * *} \\
(.0026)\end{array}$ & $\begin{array}{c}.0127^{* * *} \\
(.0025)\end{array}$ & $\begin{array}{c}.00926^{* * *} \\
(.0031)\end{array}$ \\
\hline Sample & All & All & All & Balanced \\
\hline Firm-HS8-Country FE & Yes & Yes & Yes & Yes \\
\hline Country-Year FE & - & Yes & Yes & Yes \\
\hline Firm-HS8-Year FE & - & - & Yes & Yes \\
\hline Observations & 75,277 & 75,277 & 75,277 & 18,660 \\
\hline $\mathrm{R}^{2}$ & 0.675 & 0.682 & 0.728 & 0.723 \\
\hline
\end{tabular}

Notes: The table regresses trade credit share on different measures of relationship length. Panel A uses the logarithm of cumulative FOB sales, while Panel B . All regressions are run at the transaction level (with products defined at the HS8level). Trade credit share corresponds to the ratio of the FOB value of trade credit transactions to the FOB value of all export transactions over a year. Regressions 1-2 control for the logarithm of firm employment. Standard errors (in parentheses) are clustered at the firm-product-destination level. Key: $* * *$ significant at $1 \%$; ** $5 \%$; $10 \%$.

Panel B replicates the baseline relationship specification, defining relationships at the destination level. Note that this definition is more conservative than the baseline definition: it only labels a relationship as 'new' after the first time a firm exports to a destination. Panel B shows that results are qualitatively unchanged from the baseline; even quantitatively the coefficient sizes are not too different from the baseline. If anything, trade credit use seems to react more to the relationship length when using this alternative measure. 